\title{
Molecular basis for kinin selectivity and activation of the human bradykinin receptors
}

\author{
Yu-Ling Yin ${ }^{1,2,7}$, Chenyu Ye ${ }^{3,7}$, Fulai Zhou1, Jia Wang ${ }^{1,4}$, Dehua Yang ${ }^{11,2,4}$, Wanchao Yin ${ }^{1 凶}$, \\ Ming-Wei Wang ${ }^{1,2,3,4,5,6 \bowtie, ~ H . ~ E r i c ~ X u \bowtie ~} 1,2,5 \bowtie$ and Yi Jiang ${ }^{1,2} \bowtie$
}

Bradykinin and kallidin are endogenous kinin peptide hormones that belong to the kallikrein-kinin system and are essential to the regulation of blood pressure, inflammation, coagulation and pain control. Des-Arg ${ }^{10}$-kallidin, the carboxy-terminal des-Arg metabolite of kallidin, and bradykinin selectively activate two $G$ protein-coupled receptors, type 1 and type 2 bradykinin receptors (B1R and B2R), respectively. The hyperactivation of bradykinin receptors, termed 'bradykinin storm', is associated with pulmonary edema in COVID-19 patients, suggesting that bradykinin receptors are important targets for COVID-19 intervention. Here we report two G protein-coupled complex structures of human B1R and B2R bound to des-Arg ${ }^{10}-k^{-} \mathrm{llidin}$ and bradykinin, respectively. Combined with functional analysis, our structures reveal the mechanism of ligand selectivity and specific activation of the bradykinin receptor. These findings also provide a framework for guiding drug design targeting bradykinin receptors for the treatment of inflammation, cardiovascular disorders and COVID-19.

T he kallikrein-kinin system (KKS) is a poorly understood hormonal system involved in the regulation of blood pressure, inflammation, coagulation and pain control $^{1-3}$. The main components of KKS include the metabolic products of kinin peptides, such as bradykinin, kallidin (Lys-bradykinin) and its carboxy-terminal des-Arg metabolites, derived from different kininogen isoforms ${ }^{4}$. These kinin peptides have highly conserved sequences, with kallidin differing from bradykinin only by an additional $\mathrm{N}$-terminal lysine, while des- $\mathrm{Arg}^{10}$-kallidin lacks the $\mathrm{C}$-terminal Arg relative to kallidin. They are potent vasodilators and proinflammatory peptides that activate bradykinin type 1 (B1R) and type 2 (B2R) receptors, two members of class A G protein-coupled receptors (GPCRs) ${ }^{5}$.

Hyperactivation of KKS, termed 'bradykinin storm', was reported to be closely related to COVID-19 pathogenesis. ${ }^{6}$. Gene expression analyses of the bronchoalveolar lavage fluid from COVID-19 patients revealed a dramatic upregulation of B1R by $\sim 3,000$-fold and of B2R by $\sim 200-$ fold $^{6}$, respectively. The resulting 'bradykinin storm' is thought to be responsible for most of the COVID-19 symptoms, including vascular leakage and pulmonary edema, that are linked with hyperactivation of $\mathrm{B} 1 \mathrm{R}$ and $\mathrm{B} 2 \mathrm{R}^{7}$. As such, blockade of $\mathrm{B} 1 \mathrm{R}$ and $\mathrm{B} 2 \mathrm{R}$ activation has been proposed as a therapeutic option to prevent acute respiratory distress syndrome in patients with COVID-19 (ref. ${ }^{8}$ ).

$\mathrm{B} 1 \mathrm{R}$ and $\mathrm{B} 2 \mathrm{R}$ bind to kinin-derived peptide hormones and mediate transmembrane (TM) signaling primarily through $\mathrm{G}_{\mathrm{q}}$ pathways. B2R is expressed in many normal tissues, whereas B1R expression is only induced in tissues under pathological conditions, such as inflammation ${ }^{1,9}$. B1R and B2R share $34 \%$ identity in their amino acid sequences, which are predicted to form a canonical GPCR fold of seven-transmembrane (7TM) helices, with a conserved peptide-binding pocket ${ }^{10}$. Nevertheless, kinin peptides show different selectivity for bradykinin receptor subtypes.
Specifically, bradykinin is one of the highest affinity kinin-derived peptides for B2R, but exhibits low affinity for B1R, with over 10,000 -fold selectivity ${ }^{11-13}$. In contrast, des- $\mathrm{Arg}^{10}$-kallidin dis-

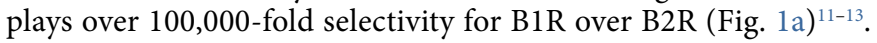
Extensive efforts have been made in defining the pharmacophore of antagonists and the molecular basis of ligand selectivity for kinins and other nonpeptides using biochemical methods and molecular modeling ${ }^{14-19}$. However, the underlying mechanisms for these peptide hormone-receptor subtypes selectivity remain largely unknown due to the lack of structural evidence. Given their important physiological and pathological properties, it is of great value to elucidate molecular mechanisms for peptide recognition and bradykinin receptor activation. Here we report two cryo-EM structures of the B1R- $\mathrm{G}_{\mathrm{q}}$ complex bound to des-Arg ${ }^{10}$-kallidin and the $\mathrm{B} 2 \mathrm{R}-\mathrm{G}_{\mathrm{q}}$ complex bound to bradykinin. Combined with mutagenesis and functional analyses, our findings provide insight into specific recognition of kinin-derived peptide hormones by $\mathrm{B} 1 \mathrm{R}$ and $B 2 R$ and the molecular basis for receptor activation and $G_{q}$ protein coupling.

\section{Results}

Structure determination of kinin-bound B1R and B2R. To stabilize B1R- $\mathrm{G}_{\mathrm{q}}$ and B2R- $\mathrm{G}_{\mathrm{q}}$ complexes, we applied the NanoBiT tethering method, a general strategy that has been used to obtain the structures of several GPCR-G protein complexes (Supplementary Fig. 1 ${ }^{20-22}$. An engineered $G \alpha_{\mathrm{q}}$ chimera was generated on the basis of the mini- $\alpha_{s / q} 71$ scaffold with its $\mathrm{N}$ terminus replaced by corresponding sequences of $\mathrm{G}_{\mathrm{i} 1}$ to facilitate the binding of scFv16

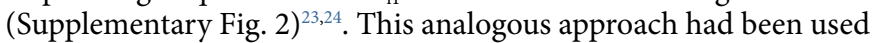
in the structure determination of the $5-\mathrm{HT}_{2 \mathrm{~A}} \mathrm{R}-\mathrm{G}_{\mathrm{q}}$ complex ${ }^{25}$. Unless otherwise specified, $G_{q}$ refers to $G_{q}$ chimera used in the structure determination. Meanwhile, both B1R and B2R bear a tryptophan mutation at position $3.41\left(\mathrm{~F} 126^{3.41} \mathrm{~W}\right.$ for $\mathrm{B} 1 \mathrm{R}$ and $\mathrm{C} 146^{3.41} \mathrm{~W}$ for

'The CAS Key Laboratory of Receptor Research, Shanghai Institute of Materia Medica, Chinese Academy of Sciences, Shanghai, China. ${ }^{2}$ University of Chinese Academy of Sciences, Beijing, China. ${ }^{3}$ School of Pharmacy, Fudan University, Shanghai, China. ${ }^{4}$ The National Center for Drug Screening, Shanghai Institute of Materia Medica, Chinese Academy of Sciences, Shanghai, China. ${ }^{5}$ School of Life Science and Technology, ShanghaiTech University, Shanghai, China. ${ }^{6}$ School of Basic Medical Sciences, Fudan University, Shanghai, China. ${ }^{7}$ These authors contributed equally: Yu-Ling Yin, Chenyu Ye.

凶e-mail:wcyin@simm.ac.cn; mwwang@simm.ac.cn; eric.xu@simm.ac.cn; yijiang@simm.ac.cn 

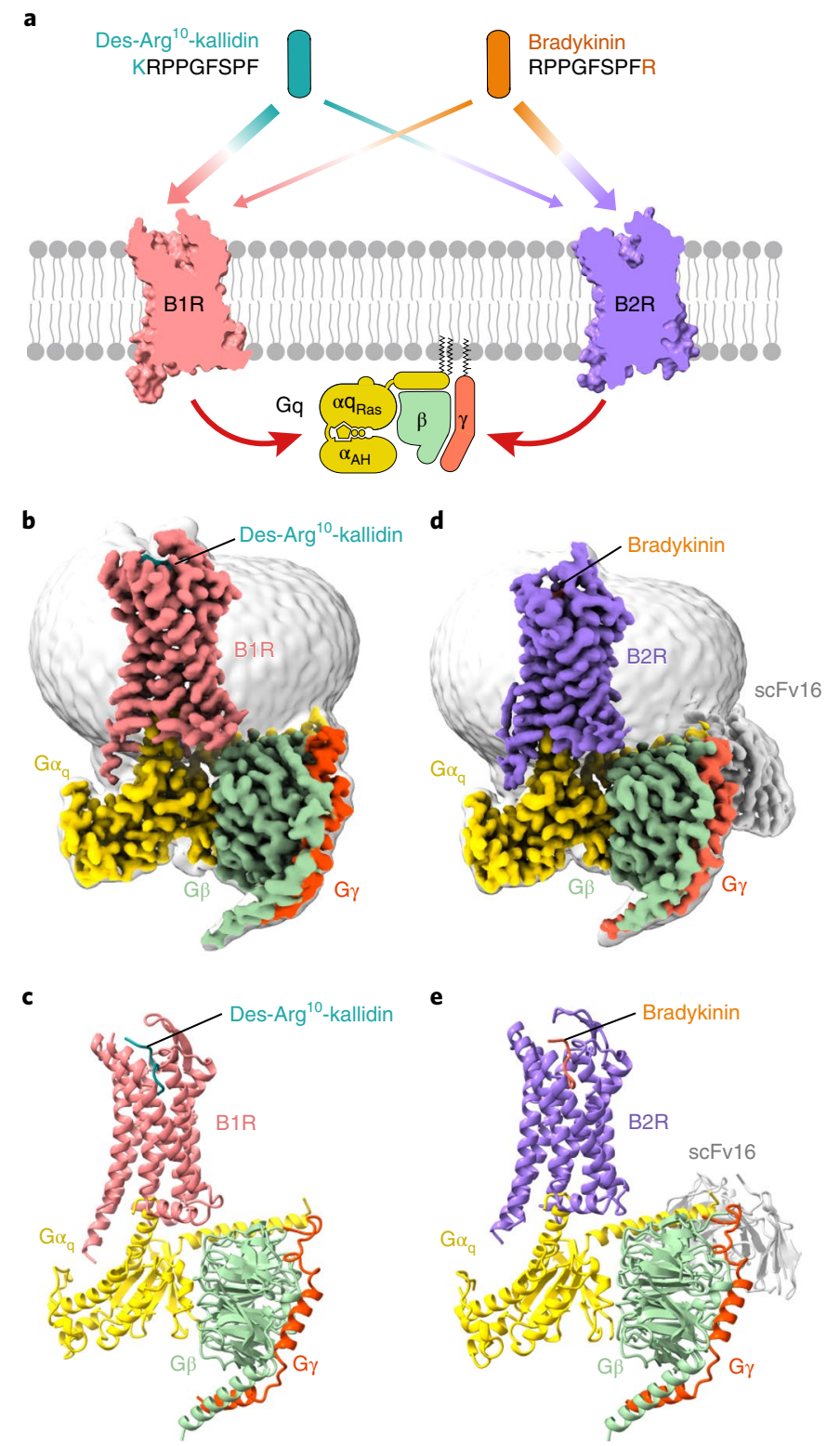

Fig. 1 | Cryo-EM structures of the des-Arg' ${ }^{10}$-kallidin-B1R- $G_{q}$ and

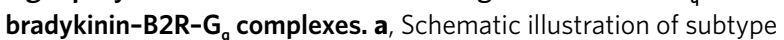
selectivity for kinin and $G_{q}$ protein coupling of bradykinin receptors. Sequences of des-Arg ${ }^{10}$-kallidin and bradykinin are shown. b,c, Orthogonal views of the density map (b) and model (c) for the des-Arg'10-kallidin-B1R$\mathrm{G}_{\mathrm{q}}$ complex. d,e, Orthogonal views of the density map (d) and model (e) for the bradykinin-B2R-G - -scFv16 complex. Des-Arg ${ }^{10}$-kallidin is shown in cyan, des-Arg ${ }^{10}$-kallidin-bound B1R in salmon; bradykinin is displayed in orange, bradykinin-bound B2R in purple. The $G_{q}$ heterotrimer is colored by subunits: $G \alpha_{q}$, yellow; $G \beta$, pale green; $G \gamma$, tomato; scFv16, gray.

$\mathrm{B} 2 \mathrm{R}$, superscripts refer to Ballesteros-Weinstein numbering ${ }^{26}$ ), a known mutation that enhanced GPCR thermal stabilization ${ }^{27,28}$. Both complexes were efficiently assembled on the membrane by coexpressing receptors with $G \alpha_{q}, G \beta 1$ and $G \gamma 2$ subunits (Extended Data Figs. 1a and 2a).

The structure of the des-Arg ${ }^{10}$-kallidin-B1R-G $\mathrm{G}_{\mathrm{q}}$ complex was defined with 633,636 final particles from 3,681,755 initial particles to a global nominal resolution of $3.0 \AA$ (Fig. 1b,c, Table 1 and Extended Data Fig. 1). The structure of the bradykinin $-B 2 R-G_{q}$ complex was

\begin{tabular}{|c|c|c|}
\hline & $\begin{array}{l}\text { B1R-G } \text { complex }_{q} \\
\text { (EMD-31145) } \\
\text { (PDB 7EIB) }\end{array}$ & $\begin{array}{l}\text { B2R-G } \text { complex } \text { com } \\
\text { (EMD-31429) } \\
\text { (PDB 7F2O) }\end{array}$ \\
\hline \multicolumn{3}{|l|}{ Data collection and processing } \\
\hline Magnification & $\times 64,000$ & $\times 81,000$ \\
\hline Voltage (kV) & 300 & 300 \\
\hline Electron exposure $\left(e-/ \AA^{2}\right)$ & 61.8 & 80 \\
\hline Defocus range $(\mu \mathrm{m})$ & -1.2 to -1.8 & -1.2 to -2.2 \\
\hline Pixel size $(\AA)$ & 1.08 & 1.045 \\
\hline Symmetry imposed & $\mathrm{C} 1$ & $\mathrm{C1}$ \\
\hline Initial particle images (no.) & $3,681,755$ & $3,460,328$ \\
\hline Final particle images (no.) & 633,636 & 664,416 \\
\hline Map resolution $(\AA)$ & 3.0 & 2.9 \\
\hline FSC threshold & 0.143 & 0.143 \\
\hline Map resolution range $(\AA)$ & 2.0 to 4.0 & 2.0 to 4.0 \\
\hline \multicolumn{3}{|l|}{ Refinement } \\
\hline $\begin{array}{l}\text { Initial model used (PDB } \\
\text { code) }\end{array}$ & $6050,6 \mathrm{WHA}$ & 6JOD, 6WHA \\
\hline Model resolution $(\AA)$ & 3.1 & 3.3 \\
\hline FSC threshold & 0.5 & 0.5 \\
\hline Map sharpening $B$ factor $\left(\AA^{2}\right)$ & -116.69 & -103.22 \\
\hline \multicolumn{3}{|l|}{ Model composition } \\
\hline Nonhydrogen atoms & 7,206 & 9,004 \\
\hline Protein residues & 928 & 1,150 \\
\hline Ligands & - & - \\
\hline \multicolumn{3}{|l|}{$B$ factors $\left(\AA^{2}\right)$} \\
\hline Protein & 59.87 & 65.10 \\
\hline Ligand & - & - \\
\hline \multicolumn{3}{|l|}{ R.m.s. deviations } \\
\hline Bond lengths $(\AA)$ & 0.006 & 0.003 \\
\hline Bond angles $\left({ }^{\circ}\right)$ & 0.904 & 0.564 \\
\hline \multicolumn{3}{|l|}{ Validation } \\
\hline MolProbity score & 1.14 & 1.49 \\
\hline Clashscore & 3.45 & 5.48 \\
\hline Poor rotamers (\%) & 0.27 & 0.41 \\
\hline \multicolumn{3}{|l|}{ Ramachandran plot } \\
\hline Favored (\%) & 98.03 & 96.81 \\
\hline Allowed (\%) & 1.97 & 3.19 \\
\hline Disallowed (\%) & 0 & 0 \\
\hline
\end{tabular}

determined with 664,416 final particles from 3,460,328 initial particles to a global nominal resolution of $2.9 \AA$ (Fig. 1d,e, Table 1 and Extended Data Fig. 2). The overall conformation comparison shows highly similarity between two receptors, with a root mean squared deviation (r.m.s.d.) of $1.0 \AA$ A. Kinin peptides, TM bundles, extracellular loops (ECLs) and intracellular loops (ICLs), except ICL3, of both receptors show clear densities, enabling near-atomic modeling for the two complexes. The majority of amino acid side chains were well resolved in the refined final model (Fig. 1b-e and Extended Data Fig. 3). Thus, these two structures can provide detailed structural information of the peptide-binding pockets and receptor- $\mathrm{G}_{\mathrm{q}}$ interaction interfaces. 
a
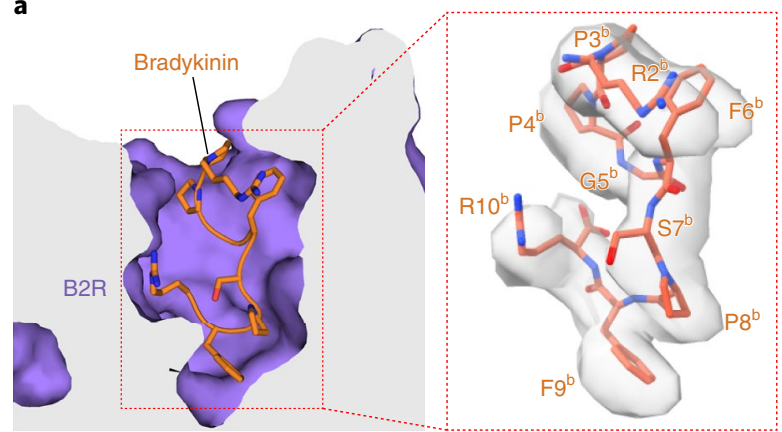

b

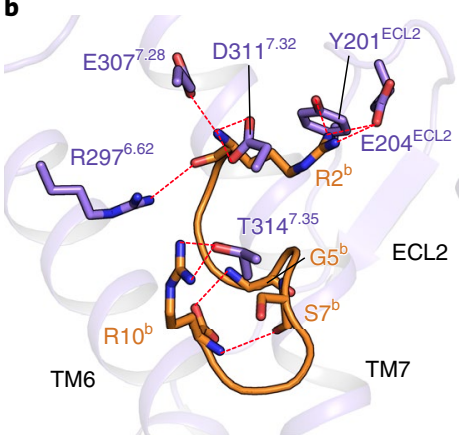

c

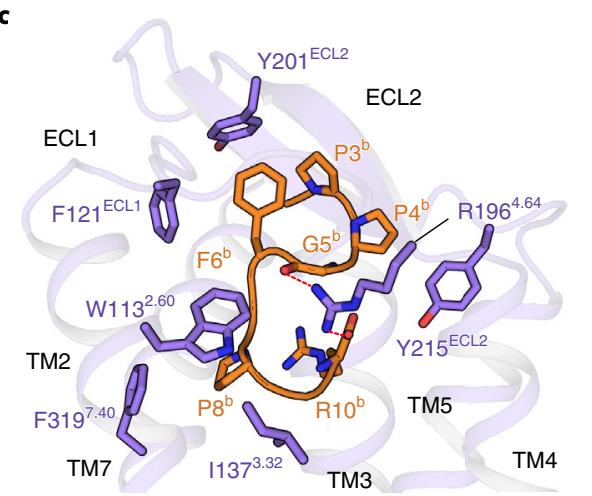

d

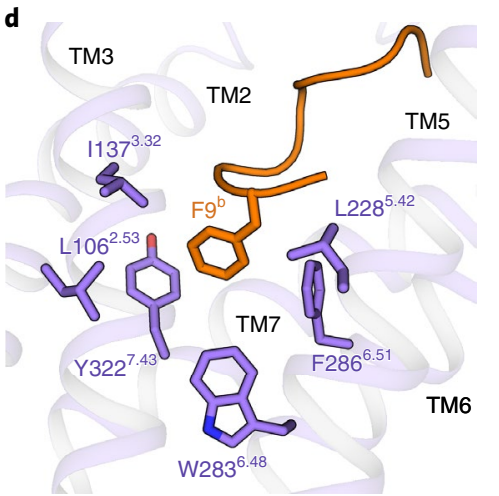

Fig. 2 | The bradykinin-binding pocket in B2R. a, Cross-section of the bradykinin-binding pocket in B2R. The cryo-EM density of bradykinin is highlighted. Side chains of the residues are displayed as sticks. Bradykinin is displayed in orange, B2R is colored in purple. b-d, Detailed interactions of bradykinin with residues in $\mathrm{B} 2 \mathrm{R}$. The binding sites of $\mathrm{R} 2^{\mathrm{b}}$ and $\mathrm{R} 10^{\mathrm{b}}(\mathbf{b}), \mathrm{P} 3^{\mathrm{b}}-\mathrm{P} 8^{\mathrm{b}}(\mathbf{c})$ and $\mathrm{F} 9^{\mathrm{b}}(\mathbf{d})$ are shown. Hydrogen bonds and salt bridge are depicted as red dashed lines.

Molecular basis of bradykinin recognition by B2R. Bradykinin (RPPGFSPFR) occupies the orthosteric binding pocket comprising TM helices and ECLs, except for TM1 and ECL3 (Extended Data Fig. 4 and Supplementary Fig. 3). It presents an S-shaped overall conformation, with its $\mathrm{C}$ terminus inserting deeply into the transmembrane domain (TMD) core (Fig. 2a). This S-shaped fold is stabilized by two intramolecular hydrogen bonds between the main chain of $\mathrm{G}^{\mathrm{b}}$ and $\mathrm{R} 10^{\mathrm{b}}$, as well as the backbone of $\mathrm{S} 7^{\mathrm{b}}$ and R10b (Fig. 2b).

The sequence of bradykinin features two positively charged arginines residing at both the $\mathrm{N}$ and $\mathrm{C}$ terminus and the majority of hydrophobic amino acids at the middle segment of the peptide. The $\mathrm{N}$-terminal R2 in bradykinin (refers to R2 ${ }^{\mathrm{b}}$ ) constitutes a stabilizing polar interaction network with ECL2, TM6 and TM7. The side chain of $\mathrm{R} 2^{\mathrm{b}}$ forms polar interactions with $\mathrm{Y} 201^{\mathrm{ECL} 2}$ and E204 ${ }^{\mathrm{ECL} 2}$. Its main chain $\mathrm{NH}$ group makes polar interactions with E307 $7^{7.28}$ and D311 $1^{7.32}$, while its backbone CO group builds a hydrogen bond with R297 $7^{6.62}$ (Fig. 2b). The C-terminal R10 ${ }^{\mathrm{b}}$ is also involved in polar interactions between bradykinin and B2R. Although the density of the guanidino group of $\mathrm{R} 10^{\mathrm{b}}$ is weak (Fig. $2 \mathrm{a}$ ), it is indicative that the side chain of $\mathrm{R} 10^{\mathrm{b}}$ forms a hydrogen bond with $\mathrm{T} 314^{7.35}$, which is supported by diminished activity of bradykinin for B2R with the T314.35 A mutation (Fig. 2b, Extended Data Fig. 5 and Supplementary Table 1). Besides R2 $2^{\mathrm{b}}$ and $\mathrm{R} 10^{\mathrm{b}}$, the main chain $\mathrm{CO}$ group of $\mathrm{G}^{\mathrm{b}}$ makes a hydrogen bond with R196 4.64 , which forms a salt bridge with the free carboxylic acid group of $\mathrm{R} 10^{\mathrm{b}}$ (Fig. 2c). The polar interaction network is essential for bradykinin-induced B2R activation, since substituting R196 1.64 with alanine entirely abolishes the activity of bradykinin (Extended Data Fig. 5 and Supplementary Table 1).

$\mathrm{P} 3^{\mathrm{b}}, \mathrm{P} 4^{\mathrm{b}}, \mathrm{F}^{\mathrm{b}}, \mathrm{P} 8^{\mathrm{b}}$ and $\mathrm{F} 9^{\mathrm{b}}$ face hydrophobic environments within the $\mathrm{B} 2 \mathrm{R}$ TMD pocket. $\mathrm{P} 3^{\mathrm{b}}$ and $\mathrm{P} 4^{\mathrm{b}}$ interact with the aromatic ring of $\mathrm{Y} 201^{\mathrm{ECL} 2}$ and $\mathrm{Y} 215^{\mathrm{ECL} 2}$, respectively (Fig. 2c). Y201 ${ }^{\mathrm{ECL} 2}$, together with $\mathrm{F} 121^{\mathrm{ECL} 1}$, makes hydrophobic contact with $\mathrm{F} 6^{\mathrm{b}}$, which is also supported by the mutagenesis analysis (Fig. 2c, Extended Data Fig. 5 and Supplementary Table 1). $\mathrm{P}^{\mathrm{b}}$ is surrounded by hydrophobic residues of TM2 (W113 $\left.{ }^{2.60}\right)$, TM3 (I137 $7^{3.32}$ ) and TM7 (F319 ${ }^{7.40}$ ) (Fig. 2c). F9 ${ }^{\mathrm{b}}$ inserts deeply into a potent hydrophobic core comprised of residues in TM2 (L106 $\left.{ }^{2.53}\right)$, TM3 (I137 $\left.7^{3.32}\right)$, TM5 (L228 $8^{5.42}$ ), TM6 (W283 ${ }^{6.48}$ and F286 $6^{6.51}$ ) and TM7 (Y322 ${ }^{7.43}$ ) (Fig. 2d). Alanine mutations of these hydrophobic residues, except for I137.3.32, show a notable impact on bradykinin-induced $\mathrm{B} 2 \mathrm{R}$ activation, indicating a potentially critical role of these hydrophobic residues near $\mathrm{F}^{\mathrm{b}}$ for bradykinin binding or B2R activation (Extended Data Fig. 5 and Supplementary Table 1). Together, these detailed structural analyses provide important information to better understand the recognition mechanism of bradykinin by B2R.

Molecular basis of des-Arg ${ }^{10}$-kallidin recognition by $\mathrm{B} 1 \mathrm{R}$. Des-Arg ${ }^{10}$-kallidin (KRPPGFSPF) shows high selectivity for B1R over B2R. Compared with bradykinin, des-Arg ${ }^{10}-$ kallidin shares a conserved middle segment (RPPGFSPF) and sits in an almost identical orthosteric binding pocket with a similar S-shaped conformation (Fig. 3a, Extended Data Fig. 4 and Supplementary Fig. 3). Nevertheless, distinct interactions are observed between two peptides and corresponding receptor subtypes, proving the basis for their receptor selectivity as described below.

In contrast to bradykinin, des- $\mathrm{Arg}^{10}$-kallidin has an additional lysine $\left(\mathrm{K} 1^{\mathrm{k}}\right)$ at its $\mathrm{N}$ terminus but lacks arginine that is located at the $\mathrm{C}$ terminus of bradykinin (R10 ${ }^{\mathrm{b}}$ ) (Fig. 3b). Two extra intramolecular hydrogen bonds exist between $\mathrm{K} 1^{\mathrm{k}}$ and the backbone $\mathrm{CO}$ group of $\mathrm{R} 2^{\mathrm{k}}$, as well as the backbone $\mathrm{CO}$ group of $\mathrm{P} 3^{\mathrm{k}}$ and $\mathrm{NH}$ group of $\mathrm{F} 6^{\mathrm{k}}$, causing a minor conformational change of des-Arg ${ }^{10}$-kallidin (Fig. 3b). The additional $\mathrm{N}$-terminal $\mathrm{K} 1^{\mathrm{k}}$ forms a polar interaction with E273 ${ }^{6.58}, \mathrm{E} 287^{7.28}$ and D291 ${ }^{7.32}$ (Fig. 3c). Intriguingly, these residues are conserved in B2R (D293 $3^{6.58}, \mathrm{E} 307^{7.28}$ and D311 $1^{7.32}$, Supplementary Fig. 3), which may explain the comparable B2R 


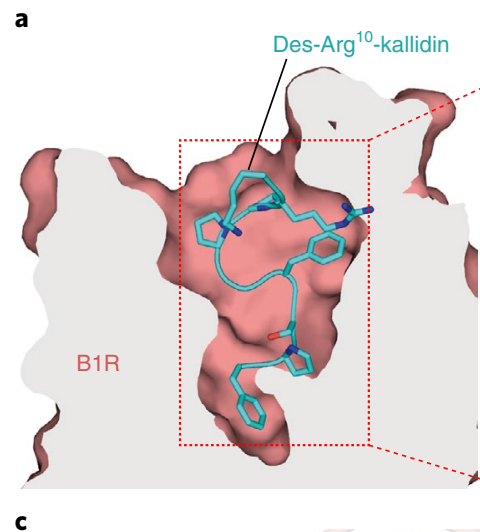

c

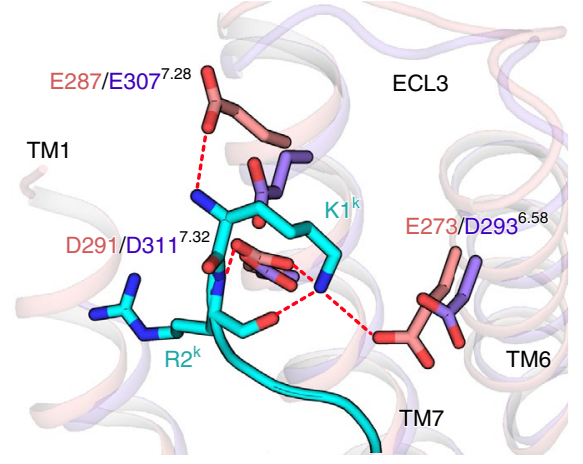

b

Des-Arg $^{10}$-kallidin

Bradykinin
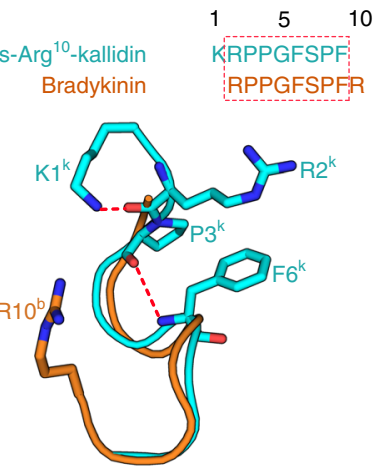

d

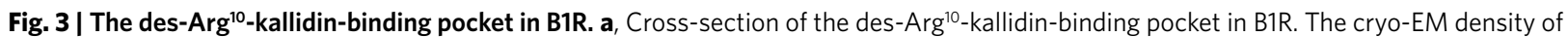
des-Arg ${ }^{10}$-kallidin is highlighted. Side chains of the residues are displayed as sticks. $\mathbf{b}$, A sequence and conformation comparison of des-Arg ${ }^{10}-k^{2}$ allidin and bradykinin. Two intramolecular hydrogen bonds are depicted as red dashed lines. Des-Arg ${ }^{10}$-kallidin is displayed in cyan, and bradykinin is colored in orange. $\mathbf{c}$, Detailed interaction between $\mathrm{K} 1^{\mathrm{k}}$ and residues in B1R. $\mathbf{d}$, Comparison of the binding mode of R2 ${ }^{\mathrm{b}}$ and $\mathrm{R} 2^{\mathrm{k}}$. The movement of ECL2 in B1R relative to that in B2R are highlighted in a red arrow. The salt bridges are shown as red dashed lines. Side chains of des-Arg ${ }^{10}-k^{-}$allidin and residues in two receptors are shown as sticks.

activation potency of Lys-bradykinin relative to bradyki$\operatorname{nin}^{12}$. Compared with $\mathrm{R} 2^{\mathrm{b}}$ in bradykinin, the equivalent $\mathrm{R} 2^{\mathrm{k}}$ in des-Arg ${ }^{10}$-kallidin presents distinct interactions with TM1 and ECL2. R2 ${ }^{\mathrm{k}}$ forms a cation-pi interaction with $\mathrm{W} 33^{1.28}$ of B1R, while $\mathrm{R} 2^{\mathrm{b}}$ pushes W53 $3^{1.28}$ away from the binding pocket owing to the steric hindrance (Fig. 3d). Additionally, ECL2 of B1R displays a smaller shift towards the peptide-binding pocket relative to $\mathrm{B} 2 \mathrm{R}$, which may be attributed to the lack of a corresponding salt bridge observed between R2 ${ }^{\text {b }}$ and E204 ${ }^{\mathrm{ECL} 2}$ in B2R (Fig. 3d).

Molecular basis of kinin selectivity for B1R and B2R. Comparison of the binding modes between the two kinin peptides provides a framework for understanding kinin peptide selectivity by B1R and $\mathrm{B} 2 \mathrm{R}$. The free carboxylic acid backbone of $\mathrm{F} 9^{\mathrm{k}}$ engages a positively charged binding pocket and forms electrostatic interactions with $\mathrm{K} 118^{3.33}$ and $\mathrm{R} 202^{5.38}$ in B1R, which are not conserved in B2R (Fig. 4a). The cognate residues $S 138^{3.33}$ and $\mathrm{T} 224^{5.38}$ in B2R fail to create a similar electrostatic environment, raising a hypothesis that the electrostatic pocket consisting of $\mathrm{K}_{11} 8^{3.33}$ and R202 $2^{5.38}$ is the determinant for selective binding of des-Arg ${ }^{10}$-kallidin to B1R over B2R. This hypothesis is supported by our mutagenesis studies showing that single or combined substitutions of $\mathrm{K} 118^{3.33}$ and R202 $2^{5.38}$ in B1R with serine and threonine, the equivalent residues in $\mathrm{B} 2 \mathrm{R}$, abolished the activity of des-Arg ${ }^{10}$-kallidin (Fig. 4b,f and Supplementary Table 2). Our results are consistent with previous reports showing that $\mathrm{K}_{11} 8^{3.33}$ attracts the negative charge of the $\mathrm{C}$ terminus of B1R-selective peptides and serves as a key residue in the selectivity of C-terminal des-Arg kinin peptides for B1 $\mathrm{R}^{18,29}$.

Compared with T224.38, F286 6.51 and D293 ${ }^{6.58}$ in B2R, the cognate residues in B1R (R202 $2^{5.38}$, Y266 $6^{6.51}$ and E273 ${ }^{6.58}$ ) are bulkier, resulting in insufficient space for interaction with the side chain of $\mathrm{R} 10^{\mathrm{b}}$ (Fig. 4c,d). The role of these residues in B2R selectivity for bradykinin is identified by swapping functional analysis. The triplicate swapping of T224 $4^{5.38} / \mathrm{F} 286^{6.51} / \mathrm{D} 293^{6.58}$ with the cognate residues with larger side chains in B1R remarkably impaired bradykinin activity (Fig. 4e and Supplementary Table 2). This finding suggests that a larger pocket consisting of T224. ${ }^{5.38}, \mathrm{~F} 286^{6.51}$ and D293 ${ }^{6.58}$ is crucial to bradykinin selectivity for B2R over B1R (Fig. 4f). Together, these data reveal the determinants of bradykinin receptor selectivity between bradykinin and des-Arg ${ }^{10}$-kallidin.

However, when mutating these kinin selectivity-related residues to cognate ones, only the $\mathrm{T} 224^{5.38} \mathrm{R}$ mutation in B2R showed slightly increased activity of des- $\mathrm{Arg}^{10}$-kallidin. Other residue substitutions did not cause substantially increased activities of bradykinin and des-Arg ${ }^{10}$-kallidin for B1R and B2R, respectively (Extended Data Fig. 5i,j). It seems that only swapping the residues in the electrostatic pocket in B1R or a larger pocket in B2R failed to make the two receptors possess high affinity for kinins. Thus, we believe that the residues in these two pockets are not entirely responsible for kinin selectivity.

Activation mechanism of B1R and B2R. A structural comparison of $\mathrm{B} 1 \mathrm{R}$ and $\mathrm{B} 2 \mathrm{R}$ complexes to their closely related angiotensin II receptor type 1 (AT1R) in the inactive (PDB 4YAY) $)^{30}$ and active states (PDB 6OS0) ${ }^{31}$ sheds light on the basis of bradykinin receptor activation. The structural comparison demonstrates that both B1R and B2R adopt fully active conformations similar to the active AT1R (Fig. 5a). Compared with the inactive AT1R, they show a remarkable outward displacement of the cytoplasmic end of TM6, a hallmark of class A GPCR activation, along with an inward movement of the TM7 cytoplasmic end (Fig. 5a,b) ${ }^{32}$. 
a

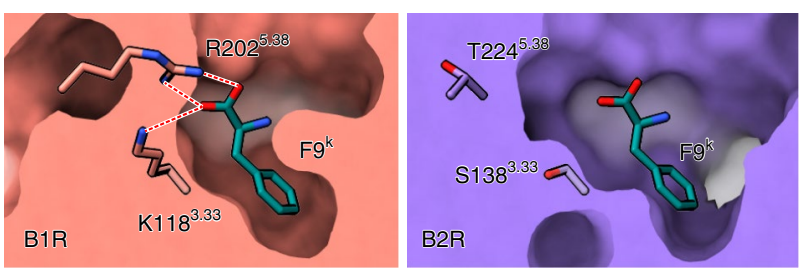

c

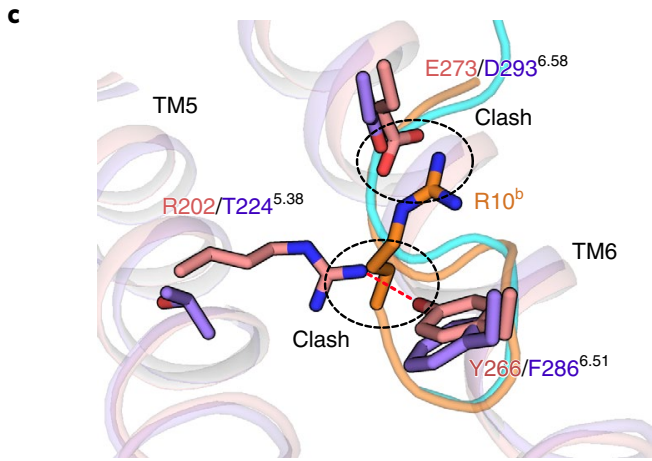

d
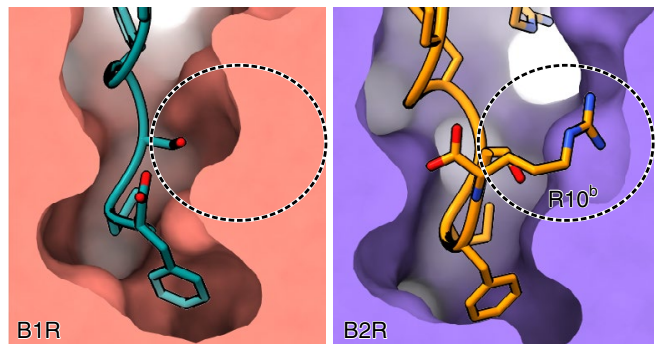

b B1R for des-Arg ${ }^{10}$-kallidin

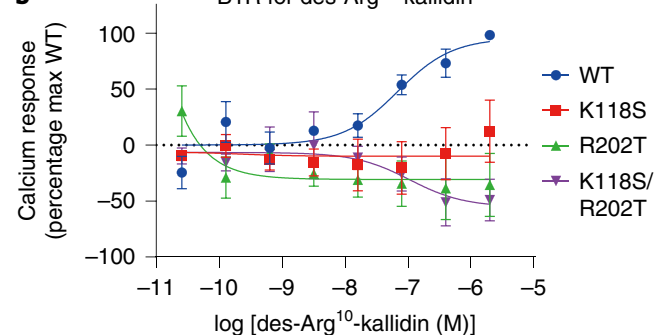

e

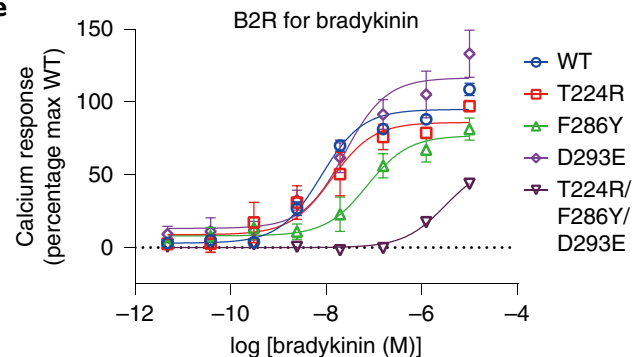

f

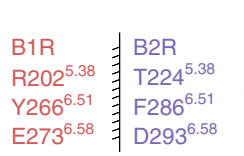

Large binding pocket

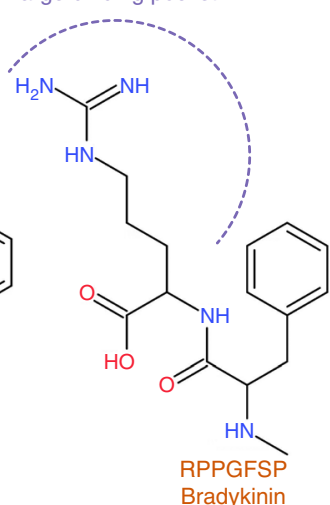

Fig. 4 | Molecular basis of kinin peptides selectivity for bradykinin receptors. a, Detailed interaction between F9k and residues in B1R. F9k and residues in B1R and the corresponding residues in B2R are shown as sticks. b. Effects of mutations in the F9k-binding pocket on calcium responses. Data are presented as mean \pm s.e.m. of three independent experiments. c, The binding site of R10 ${ }^{b}$. Residues in the R10 ${ }^{b}$-binding site in B2R and cognate residues in B1R are shown. The steric clash between side chain of R10 $0^{\mathrm{b}}$ and residues in B1R are highlighted as black dashed ovals. Polar interactions in $\mathbf{a}$ and $\mathbf{c}$ are shown as red dashed lines. d, A larger R10 binding pocket in B2R relative to B1R. The pockets are highlighted as black dashed ovals. e, Effects of mutations in the R10 ${ }^{b}$-binding pocket on calcium responses. e, Schematic model of the molecular basis of kinin peptide selectivity for bradykinin receptors. The chemical structures of $\mathrm{F}^{\mathrm{k}}$ in des-Arg ${ }^{10}$-kallidin as well as $\mathrm{F}^{\mathrm{b}}$ and $\mathrm{R} 10^{\mathrm{b}}$ in bradykinin are displayed. Residues in the positively charged pocket of B1R and the large binding pocket of B2R are highlighted. Data for $\mathbf{b}$ and $\mathbf{e}$ are displayed in Supplementary Table 2. Each data point presents mean \pm s.e.m. of three independent experiments. WT, wild type. Source data for $\mathbf{b}$ and $\mathbf{e}$ are available online.

Although bradykinin and des-Arg ${ }^{10}$-kallidin present different binding selectivity, they may activate bradykinin receptors through a common mechanism. The side chains of $\mathrm{F}^{\mathrm{b}}$ and $\mathrm{F}^{\mathrm{k}}$ insert into a conserved hydrophobic crevice at the bottom of the peptide-binding pocket and trigger rotameric switch of $\mathrm{W}^{6.48}$, the toggle switch residue, which further facilitates the swing of $\mathrm{F}^{6.44}$ and initiates the rotation of TM6 (Fig. 5c). Meanwhile, the steric clash between $\mathrm{F}^{\mathrm{k}} / \mathrm{F}^{\mathrm{b}}$ and $\mathrm{F} / \mathrm{Y}^{7.43}$ would drive the latter swinging away from the receptor helical core and the inward shifting of the cytoplasmic end of TM7 (Fig. 5c). [ Leu $^{9}$, des-Arg $\left.{ }^{10}\right]$ kallidin, in which $\mathrm{F}^{\mathrm{k}}$ of des- $\mathrm{Arg}^{10}$-kallidin is substituted with a smaller bulky amino acid (leucine), loses its agonistic activity with conversion to a B1R antagonist, supporting the critical role of $\mathrm{F}^{\mathrm{k}}$ in $\mathrm{B} 1 \mathrm{R}$ activation ${ }^{33,34}$. The switches of $\mathrm{W}^{6.48}$ and $\mathrm{F} / \mathrm{Y}^{7.43}$ further trigger the active-like conformational changes of 'micro-switch' residues (toggle switch $\mathrm{W}^{6.48}$ and PIF, DRY and NPxxY motifs), leading to an agonism signal transduction to the cytoplasmic end of the receptor (Fig. 5c-f).
Structural comparison of B1R and B2R with their closely related class A GPCR member AT1R in the active state (PDB 6OS0) ${ }^{31}$ suggests a common mechanism of receptor activation. The bound endogenous peptide hormones des-Arg ${ }^{10}$-kallidin, bradykinin and angiotensin II share conserved C-terminal phenylalanine, which inserts into the peptide-binding pockets of corresponding receptors at a comparable depth (Extended Data Fig. 6a,b). Moreover, although differing in side chain orientations, these phenylalanines are buried within a similar hydrophobic environment, indicating a universal activation mechanism of these closely related GPCRs (Extended Data Fig. 6c).

Structural superposition of $\mathrm{G}_{\mathrm{q}}$-coupled B1R and B2R complexes with the $\mathrm{G}_{\mathrm{q}}$-coupled 5- $\mathrm{HT}_{2 \mathrm{~A}} \mathrm{R}$ (PDB 6WHA) ${ }^{25}$ and $\mathrm{G}_{11}$-coupled M1R $(\mathrm{PDB} 6 \mathrm{OIJ})^{35}$ by receptors shows nearly identical conformations of TM6 and TM7 (Extended Data Fig. 7a), suggest that $\mathrm{G}_{\mathrm{q}}$-coupled receptors have a similar conformation to that of $\mathrm{G}_{11}$-coupled receptors. In addition, compared with these two $\mathrm{G}_{q / 11}$-coupled receptors, the helix 8 of B1R and B2R is closer to the G $\beta$ subunit, which may 


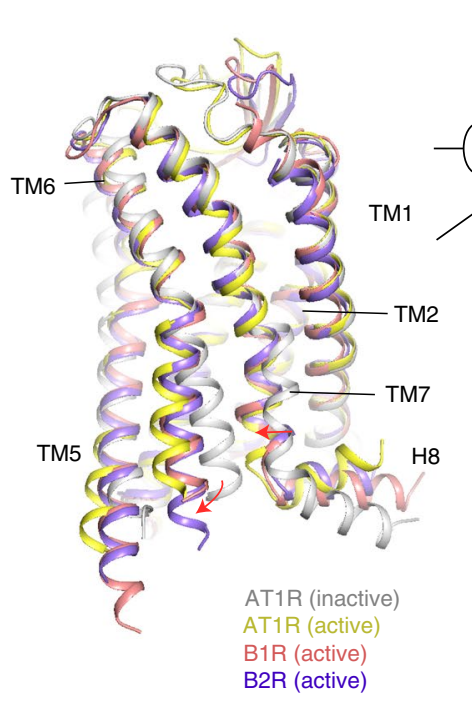

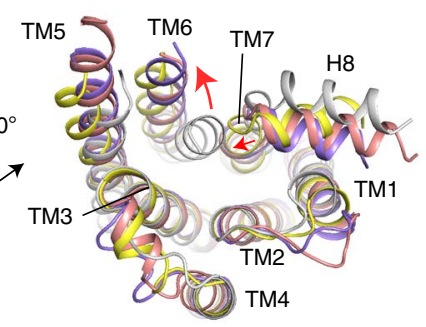

c

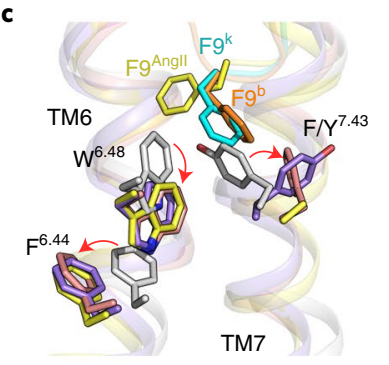

d

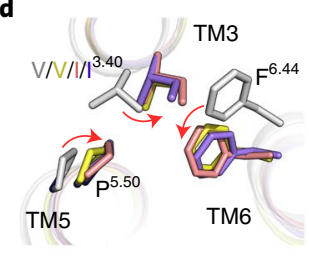

e
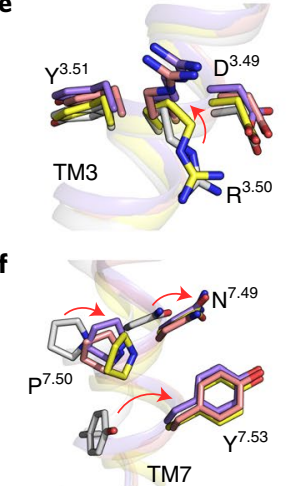

Fig. 5 | Activation mechanism of bradykinin receptors. a,b, Structural superposition of two active bradykinin receptors, inactive AT1R (PDB 4YAY), and active AT1R (PDB 6OSO) from the side (a) and cytoplasmic (b) views. The movement directions of TM6 and TM7 in bradykinin receptors relative to inactive AT1R are highlighted as red arrows. AT1R, angiotensin II receptor type 1. Inactive AT1R, active AT1R, B1R and B2R are colored in gray, yellow, salmon and purple, respectively. c-f, Conformational changes of the conserved 'micro-switches' upon receptor activation, including toggle switch (c), PIF (d), DRY (e) and $\mathrm{NPxx}$ (f) motifs. F9' $/$ F9 $^{\mathrm{k}}$-triggered conformational changes of $\mathrm{W}^{6.48}$ and $\mathrm{Y}^{7.43}$ are highlighted. The conformational changes of residue side chains are shown as red arrows upon receptor activation. The complex structures were aligned by the receptors.

be attributed to the intramolecular salt bridge formed between $\mathrm{K}^{8.53}$ and $\mathrm{E}^{2.40}$ (Extended Data Fig. $7 \mathrm{~b}$ ). On the $\mathrm{G}$ protein side, the $\alpha 5$ helix of $\mathrm{G} \alpha_{\mathrm{q}}$ shifts $4 \AA$ for both B1R and B2R compared with that of $\mathrm{G}_{11}$-coupled M1R (measured at $\mathrm{C} \alpha$ of $\mathrm{Y}^{\mathrm{H} 5.23}$ ) and moves a half-helical turn upward towards the cytoplasmic cavity of the receptor ( $2 \AA$ for $\mathrm{B} 1 \mathrm{R}$ and $3 \AA$ for $\mathrm{B} 2 \mathrm{R}$, respectively) relative to the $\mathrm{G}_{\mathrm{q}}$-coupled $5-\mathrm{HT}_{2 \mathrm{~A}} \mathrm{R}$. Meanwhile, the $\mathrm{G} \alpha_{\mathrm{q}} \mathrm{N}$ termini of $\mathrm{B} 1 \mathrm{R}$ and B2R undergo notable shifts as seen across the $G_{q / 11}$-coupled class $A$ GPCRs (Extended Data Fig. 7c).

\section{Discussion}

Bradykinin receptors are involved in various clinical symptoms and their use as therapeutic targets remains the focus of extensive investigations. Recently, decoding the bradykinin inflammatory pathway in COVID-19, known as the 'bradykinin storm', highlights the implications of bradykinin receptor modulators as a potential treatment for COVID-19. In this study, we determined two $\mathrm{G}_{\mathrm{q}}$-coupled structures of the human $\mathrm{B} 1 \mathrm{R}$ and $\mathrm{B} 2 \mathrm{R}$ bound to selective kinin peptides: des-Arg ${ }^{10}$-kallidin and bradykinin, respectively. In combination with functional analyses, these structures enhance our understanding of the molecular basis of kinin peptide recognition and activation of B1R and B2R.

Intriguingly, it has recently been predicted that des-Arg ${ }^{10}$-kallidin and bradykinin show distinct V- and S-shaped conformations, respectively. These distinct conformations result in different presentations of the $\mathrm{N}$ and $\mathrm{C}$ termini of kinin peptides towards their receptors $^{18}$. In our structural model, bradykinin adopts an overall similar S-shaped conformation, but notably differs in the orientation of the C-terminal charged arginine $\left(\mathrm{R} 10^{\mathrm{b}}\right)$, with an overall r.m.s.d. of $1.8 \AA$ (Extended Data Fig. 8a). The side chain of R10 $10^{\mathrm{b}}$ sits in the gap between TM6 and TM7 and forms a salt bridge with T314 ${ }^{7.35}$. In contrast, $\mathrm{R} 10^{\mathrm{b}}$ points to TM5 and forms a salt bridge with E221 $1^{5.35}$ in the predicted model. It is worth noting that des-Arg ${ }^{10}$-kallidin in the structural model shows an entirely different conformation, presenting an S-shaped but not a V-shaped fold, with an r.m.s.d. of $3.4 \AA$ (Extended Data Fig. 8b). Even so, the middle segment of des-Arg ${ }^{10}$-kallidin $\left(\mathrm{P}^{\mathrm{k}}{ }^{\mathrm{k}}-\mathrm{F}^{\mathrm{k}}\right)$ in both our structure and NMR model displays a similar $\beta$-turn-like conformation, which might be stabilized by the intramolecular hydrogen bond made by the backbone $\mathrm{NH}$ of $\mathrm{F}^{\mathrm{k}}$ and $\mathrm{CO}$ of $\mathrm{P} 3^{\mathrm{k}}$, as observed in the B1R complex structure. A des-Arg ${ }^{10}$-kallidin analog with the methylated amide of $\mathrm{F}^{\mathrm{k}}$, which may disturb this hydrogen bond and central $\beta$-turn, showed a 1,000-fold lower binding affinity for $\mathrm{B} 1 \mathrm{R}$ than the native peptide, indicating the importance of this intramolecular interaction in maintaining the conformation stability of des- $\operatorname{Arg}^{10}{ }^{10}$ allidin $^{18}$. It was predicted that the $\mathrm{C}$-terminal segment of bradykinin $\left(\mathrm{S} 7^{\mathrm{b}}-\mathrm{R} 10^{\mathrm{b}}\right)$ adopted a $\beta$-turn conformation, which might be one of the requirements for high affinity to $B 2 R^{17}$. The $\beta$-turn constitutes a molecular basis for designing B2R ligands, including the only approved B2R antagonist, icatibant ${ }^{16,17}$. Consistently, we also observed a similar $\beta$-turn conformation, which is stabilized by two intramolecular hydrogen bonds in the $\mathrm{B} 2 \mathrm{R}$ structure. This $\beta$-turn forces $\mathrm{F}^{\mathrm{b}}$ to insert deeply into the TMD core and engage with hydrophobic residues at the bottom of the $\mathrm{B} 2 \mathrm{R}$ pocket. Our alanine mutagenesis analysis on these hydrophobic residues further supports a potential role of the $\beta$-turn conformation of bradykinin in B2R activation.

Bradykinin receptors exhibit exquisite selectivity for bradykinin and des-Arg ${ }^{10}$-kallidin, and our findings provide a framework to depict the subtype selectivity of kinin peptides for B1R and B2R. It was found that the residue environments surrounding the $C$ termini amino acids of bradykinin and des- $\mathrm{Arg}^{10}$-kallidin are critical to such selectivity. K1 $18^{3.33}$ and $\mathrm{R} 202^{5.38}$, which constitute a positively charged pocket interacting with the free carboxylic acid group of $\mathrm{F}^{\mathrm{k}}$, are determinants of the preference of des- $\mathrm{Arg}^{10}$-kallidin for B1R. Additionally, the hydrogen bond between R202 $2^{5.38}$ and Y266 ${ }^{6.51}$ in B1R creates an inaccessible space for bradykinin. Meanwhile, the smaller side chains of T224 $4^{5.38}, \mathrm{~F} 286^{6.51}$ and D2936.58 in B2R, relative to equivalent residues in $\mathrm{B} 1 \mathrm{R}$, create a larger pocket space to accommodate $\mathrm{R} 10^{\mathrm{b}}$, thereby revealing the molecular basis of the higher B2R selectivity by bradykinin. Coincidentally, the NMR model 
predictedthesamehydrogenbondbetween R202 $2^{5.38}$ andY266 $6^{6.51}\left(\right.$ ref. $\left.^{18}\right)$. A molecular modeling study on B1R and B2R also speculated that the smaller size of $T^{5.38}$ in $B 2 R$, relative to cognate residue $R^{5.38}$ in $\mathrm{B} 1 \mathrm{R}$, allows nonpeptide antagonists to access an aromatic pocket composed of $\mathrm{W}^{6.48}, \mathrm{~F}^{6.51}$ and $\mathrm{Y}^{7.43}$, which is inaccessible for $\mathrm{B}^{1} \mathrm{R}^{15,16,19}$. However, $\mathrm{R} / \mathrm{T}^{5.38}$ in $\mathrm{B} 1 \mathrm{R}$ and $\mathrm{B} 2 \mathrm{R}$ cannot hamper the engagement of kinins with this aromatic pocket, which accommodates $\mathrm{F}^{\mathrm{k}} / \mathrm{F}^{\mathrm{b}}$ in our structures. Conversely, $\mathrm{R} / \mathrm{T}^{5.38}$ is involved in the binding of $\mathrm{R} 10^{\mathrm{b}}$ to a larger pocket in $\mathrm{B} 2 \mathrm{R}$, which partially determines bradykinin selectivity for B2R over B1R. Additionally, we further propose a common activation mechanism for B1R and B2R, through structural comparison with AT1R. With an in-depth knowledge of ligand selectivity and receptor activation, new opportunities will arise to design potent and efficacious modulators of $\mathrm{B} 1 \mathrm{R}$ and $\mathrm{B} 2 \mathrm{R}$ for the treatment of inflammation, cardiovascular disorders and COVID-19.

\section{Online content}

Any methods, additional references, Nature Research reporting summaries, source data, extended data, supplementary information, acknowledgements, peer review information; details of author contributions and competing interests; and statements of data and code availability are available at https://doi.org/10.1038/ s41594-021-00645-y.

Received: 24 March 2021; Accepted: 19 July 2021;

Published online: 9 September 2021

\section{References}

1. Dray, A. \& Perkins, M. Bradykinin and inflammatory pain. Trends Neurosci. 16, 99-104 (1993)

2. Waeber, B. \& Brunner, H. R. Cardiovascular hypertrophy: role of angiotensin II and bradykinin. J. Cardiovasc. Pharmacol. 27, S36-S40 (1996).

3. Tomita, H., Sanford, R. B., Smithies, O. \& Kakoki, M. The kallikrein-kinin system in diabetic nephropathy. Kidney Int. 81, 733-744 (2012).

4. Marceau, F. \& Regoli, D. Bradykinin receptor ligands: therapeutic perspectives. Nat. Rev. Drug Discov. 3, 845-852 (2004).

5. Marceau, F. et al. Bifunctional ligands of the bradykinin B2 and B1 receptors: an exercise in peptide hormone plasticity. Peptides 105, 37-50 (2018).

6. Garvin, M. R. et al. A mechanistic model and therapeutic interventions for COVID-19 involving a RAS-mediated bradykinin storm. eLife 9, e59177 (2020).

7. Zwaveling, S., Gerth van Wijk, R. \& Karim, F. Pulmonary edema in COVID-19: explained by bradykinin? J. Allergy Clin. Immunol. 146, 1454-1455 (2020).

8. van de Veerdonk, F. L. et al. Kallikrein-kinin blockade in patients with COVID-19 to prevent acute respiratory distress syndrome. eLife $\mathbf{9}$, e57555 (2020).

9. McEachern, A. E. et al. Expression cloning of a rat B2 bradykinin receptor. Proc. Natl Acad. Sci. USA 88, 7724-7728 (1991).

10. Surgand, J. S., Rodrigo, J., Kellenberger, E. \& Rognan, D. A chemogenomic analysis of the transmembrane binding cavity of human G-protein-coupled receptors. Proteins 62, 509-538 (2006).

11. Bastian, S., Loillier, B., Paquet, J. L. \& Pruneau, D. Stable expression of human kinin B1 receptor in 293 cells: pharmacological and functional characterization. Br. J. Pharmacol. 122, 393-399 (1997).

12. Hess, J. F. et al. Differential pharmacology of cloned human and mouse B2 bradykinin receptors. Mol. Pharmacol. 45, 1-8 (1994).
13. Leeb-Lundberg, L. M., Marceau, F., Muller-Esterl, W., Pettibone, D. J. \& Zuraw, B. L. International Union of Pharmacology. XLV. Classification of the kinin receptor family: from molecular mechanisms to pathophysiological consequences. Pharm. Rev. 57, 27-77 (2005).

14. Meini, S. et al. Site-directed mutagenesis at the human B2 receptor and molecular modelling to define the pharmacophore of non-peptide bradykinin receptor antagonists. Biochem. Pharmacol. 67, 601-609 (2004).

15. Lupala, C. S., Gomez-Gutierrez, P. \& Perez, J. J. New insights into the stereochemical requirements of the bradykinin B1 receptor antagonists binding. J. Mol. Graph. Model. 68, 184-196 (2016).

16. Lupala, C. S., Gomez-Gutierrez, P. \& Perez, J. J. New insights into the stereochemical requirements of the bradykinin B2 receptor antagonists binding. J. Comput. Aided Mol. Des. 30, 85-101 (2016).

17. Lopez, J. J. et al. The structure of the neuropeptide bradykinin bound to the human G-protein coupled receptor bradykinin B2 as determined by solid-state NMR spectroscopy. Angew. Chem. Int. Ed. Engl. 47, 1668-1671 (2008).

18. Joedicke, L. et al. The molecular basis of subtype selectivity of human kinin G-protein-coupled receptors. Nat. Chem. Biol. 14, 284-290 (2018).

19. Rasaeifar, B., Lupala, C. S., Gomez-Gutierrez, P. \& Perez, J. J. Molecular features characterizing non-peptide selectivity to the human B1 and B2 bradykinin receptors. Bioorg. Med. Chem. Lett. 29, 11-14 (2019).

20. Duan, J. et al. Cryo-EM structure of an activated VIP1 receptor-G protein complex revealed by a NanoBiT tethering strategy. Nat. Commun. 11, 4121 (2020).

21. Sun, W. et al. A unique hormonal recognition feature of the human glucagon-like peptide-2 receptor. Cell Res. 30, 1098-1108 (2020).

22. Zhou, F. et al. Structural basis for activation of the growth hormone-releasing hormone receptor. Nat. Commun. 11, 5205 (2020).

23. Nehme, R. et al. Mini-G proteins: novel tools for studying GPCRs in their active conformation. PLoS ONE 12, e0175642 (2017).

24. Koehl, A. et al. Structure of the mu-opioid receptor-Gi protein complex. Nature 558, 547-552 (2018).

25. Kim, K. et al. Structure of a hallucinogen-activated Gq-coupled 5-HT2A serotonin receptor. Cell 182, 1574-1588.e19 (2020).

26. Ballesteros, J. A. \& Weinstein, H. Methods in Neurosciences, Vol. 25 (ed. Sealfon, S. C.) 366-428 (Academic Press, 1995).

27. Popov, P. et al. Computational design of thermostabilizing point mutations for G protein-coupled receptors. Elife 7, e34729 (2018).

28. Roth, C. B., Hanson, M. A. \& Stevens, R. C. Stabilization of the human $\beta_{2}$-adrenergic receptor TM4-TM3-TM5 helix interface by mutagenesis of Glu122 $2^{3.41}$, a critical residue in GPCR structure. J. Mol. Biol. 376, 1305-1319 (2008).

29. Fathy, D. B., Mathis, S. A., Leeb, T. \& Leeb-Lundberg, L. M. A single position in the third transmembrane domains of the human B1 and B2 bradykinin receptors is adjacent to and discriminates between the $\mathrm{C}$-terminal residues of subtype-selective ligands. J. Biol. Chem. 273, 12210-12218 (1998).

30. Zhang, H. et al. Structure of the angiotensin receptor revealed by serial femtosecond crystallography. Cell 161, 833-844 (2015).

31. Wingler, L. M. et al. Angiotensin and biased analogs induce structurally distinct active conformations within a GPCR. Science 367, 888-892 (2020).

32. Latorraca, N. R., Venkatakrishnan, A. J. \& Dror, R. O. GPCR dynamics: structures in motion. Chem. Rev. 117, 139-155 (2017).

33. Menke, J. G. et al. Expression cloning of a human B1 bradykinin receptor. J. Biol. Chem. 269, 21583-21586 (1994).

34. Marceau, F., Hess, J. F. \& Bachvarov, D. R. The B1 receptors for kinins. Pharm. Rev. 50, 357-386 (1998).

35. Maeda, S., Qu, Q., Robertson, M. J., Skiniotis, G. \& Kobilka, B. K. Structures of the M1 and M2 muscarinic acetylcholine receptor/G-protein complexes. Science 364, 552-557 (2019).

Publisher's note Springer Nature remains neutral with regard to jurisdictional claims in published maps and institutional affiliations.

(c) The Author(s), under exclusive licence to Springer Nature America, Inc. 2021 


\section{Methods}

Construct cloning. Homo sapiens B1R, residues 2-350 of the 353 residues (UniProt accession: P46663) with an N-terminal thermostabilized apocytochrome $\mathrm{b}_{562}$ RIL (BRIL) ${ }^{36}$ and a C-terminal LgBiT were cloned into pFastBac. Before BRIL, there are HA and FLAG tags followed by a His10 (H10) tag, as well as a TEV cleavage site. For Homo sapiens B2R (UniProt accession: P30411), residues 40-370 of the 391 residues with an N-terminal HA tag followed by BRIL and a C-terminal $\mathrm{LgBiT}$ were cloned into pFastBac using homologous recombination (CloneExpress One Step Cloning Kit, Vazyme). Another TEV cleavage site and the tandem maltose-binding protein tag after $\mathrm{LgBiT}$ were added to both $\mathrm{B} 1 \mathrm{R}$ and $\mathrm{B} 2 \mathrm{R}$ constructs to facilitate expression and purification. The engineered $\mathrm{G} \alpha_{\mathrm{q}}$ construct was generated on the basis of mini- $\mathrm{G}_{\mathrm{s} / \mathrm{q}} 71$ (ref. ${ }^{23}$ ) with two dominant-negative mutations (corresponding to G203A and A326S) ${ }^{37}$ to decrease the affinity of nucleotide binding. The N-terminal 1-18 amino acids and the $\alpha$-helical domain of the mini- $\mathrm{G}_{\mathrm{s} / \mathrm{q}} 71$ were replaced by the corresponding sequences of the human $G \alpha_{i 1}$, providing possible binding sites for two antibody fragments scFv16 and Fab-G50, respectively ${ }^{35,38}$. Rat G $\beta 1$ with an $\mathrm{N}$-terminal His6 tag was followed by HiBiT at its $\mathrm{C}$ terminus. The engineered $\mathrm{G} \alpha_{q}, \mathrm{G} \beta 1$ and bovine $\mathrm{G} \gamma 2$ were cloned into the pFastBac vector (Invitrogen).

Expression and purification of Nb35. $\mathrm{Nb35}$ (ref. ${ }^{39}$ ) with a C-terminal His6 tag was expressed in Escherichia coli BL21 (DE3) bacteria, and cultured in LB medium with $50 \mu \mathrm{g} \mathrm{ml}^{-1}$ ampicillin to an optical density $\left(\mathrm{OD}_{600}\right)$ value of $0.6-1.0$ at $37^{\circ} \mathrm{C}$, 180 r.p.m. IPTG $(1 \mathrm{mM})$ was added to induce expression at $27^{\circ} \mathrm{C}, 180$ r.p.m for 8 h. E. coli bacteria were then collected by centrifugation $(4,000$ r.p.m., $20 \mathrm{~min})$ and disrupted in $20 \mathrm{mM}$ HEPES, pH 7.4, $100 \mathrm{mM} \mathrm{NaCl}, 10 \%$ glycerol and $1 \mathrm{mM}$ PMSF. Cell pellets were removed by centrifugation (8,000 r.p.m., $30 \mathrm{~min}$ ) and the supernatant was purified by nickel affinity chromatography (Ni Smart Beads 6FF, Smart Life Sciences). The resin was washed with 30 column volumes of buffer containing $20 \mathrm{mM}$ HEPES pH 7.4, $100 \mathrm{mM} \mathrm{NaCl}, 25 \mathrm{mM}$ imidazole, $10 \%$ glycerol, and the eluted protein was collected with buffer containing $20 \mathrm{mM}$ HEPES $\mathrm{pH} 7.4,100 \mathrm{mM} \mathrm{NaCl}, 200 \mathrm{mM}$ imidazole and $10 \%$ glycerol. The eluted Nb35 was concentrated and subjected to a HiLoad 16/600 Superdex 75 column (GE Healthcare) pre-equilibrated with buffer containing $20 \mathrm{mM}$ HEPES pH 7.4 and $100 \mathrm{mM} \mathrm{NaCl}$. The monomeric fractions were collected and stored with $30 \%(\mathrm{v} / \mathrm{v})$ glycerol at $-80^{\circ} \mathrm{C}$ for future use.

Expression and purification of scFv16. ScFv16 with a C-terminal His8 tag was expressed in High Five insect cells and purified as previously described ${ }^{24}$. In detail, the cells infected with scFv16 virus for $48 \mathrm{~h}$ were removed by centrifugation (2,000 r.p.m., $20 \mathrm{~min})$. The supernatant was balanced with Tris $\mathrm{pH} 8.0$ and then quenched with chelating agents $\left(1 \mathrm{mM} \mathrm{NiCl}_{2}\right.$ and $\left.5 \mathrm{mM} \mathrm{CaCl}_{2}\right)$ at room temperature for $1 \mathrm{~h}$. Precipitates were removed by centrifugation $(8,000$ r.p.m., $30 \mathrm{~min}$ ) and the supernatant was purified by nickel affinity chromatography as described above.

Expression and purification of $B 1 R / B 2 R-G_{q}$ complex. High Five cells were infected with viruses of the receptor (B1R or B2R), G $\alpha_{q}, G \beta 1$ and $G \gamma 2$ in the ratio of $1: 1: 1: 1$ for $48 \mathrm{~h}$ at $27^{\circ} \mathrm{C}$. The cell pellets were lysed by dounce homogenization in $20 \mathrm{mM}$ HEPES pH 7.4, $100 \mathrm{mM} \mathrm{NaCl}, 10 \mathrm{mM} \mathrm{MgCl}_{2}$, $5 \mathrm{mM} \mathrm{CaCl}_{2}, 10 \%$ glycerol and EDTA-free protease inhibitor cocktail (TargetMol). The supernatant was then centrifuged at 30,000 r.p.m. for $30 \mathrm{~min}$ to collect the membranes. The washed membranes were re-suspended in $20 \mathrm{mM}$ HEPES $\mathrm{pH} 7.4,100 \mathrm{mM} \mathrm{NaCl}, 10 \mathrm{mM} \mathrm{MgCl}_{2}, 5 \mathrm{mM} \mathrm{CaCl}_{2}, 10 \%$ glycerol, $40 \mu \mathrm{M}$ peptide (des-Arg ${ }^{10}$-kallidin for B1R and bradykinin for B2R, respectively, GenScript), $25 \mathrm{mU} \mathrm{ml}^{-1}$ apyrase (Sigma-Aldrich), $100 \mu \mathrm{M}$ TCEP (Sigma-Aldrich), EDTA-free protease inhibitor cocktail and $20 \mu \mathrm{g} \mathrm{ml}^{-1} \mathrm{Nb35}$, and incubated at $4^{\circ} \mathrm{C}$ overnight. For the B2R- $\mathrm{G}_{\mathrm{q}}$ complex, an additional $20 \mu \mathrm{g} \mathrm{ml}^{-1} \mathrm{scFv16}$ was added. After incubation, $0.5 \%$ (w/v) $n$-dodecyl- $\beta$-D-maltopyranoside (DDM, Anatrace) and $0.1 \%(\mathrm{w} / \mathrm{v})$ cholesteryl hemisuccinate (CHS, Anatrace) were used for solubilization at $4{ }^{\circ} \mathrm{C}$ for $3 \mathrm{~h}$. The supernatant was collected by centrifugation at 30,000 r.p.m. for $30 \mathrm{~min}$ and then incubated with dextrin resin (Dextrin Beads 6FF, Smart Life Sciences) at $4^{\circ} \mathrm{C}$ for $3 \mathrm{~h}$. The resin was collected by centrifugation at $500 \mathrm{~g}$ for $8 \mathrm{~min}$, loaded onto a gravity flow column and washed with 10 column volumes of buffer containing $20 \mathrm{mM}$ HEPES pH 7.4, $100 \mathrm{mM} \mathrm{NaCl}, 10 \mathrm{mM} \mathrm{MgCl}, 5 \mathrm{mM}$ $\mathrm{CaCl}_{2}, 10 \%$ glycerol, $100 \mu \mathrm{M}$ TCEP, $40 \mu \mathrm{M}$ peptide, $0.05 \%$ (w/v) DDM and $0.01 \%(\mathrm{w} / \mathrm{v}) \mathrm{CHS}$. The detergent of washing buffer was then displaced by $0.1 \%$ (w/v) lauryl maltose neopentylglycol (LMNG, Anatrace) and $0.02 \%(\mathrm{w} / \mathrm{v}) \mathrm{CHS}$ for 10 column volumes washing, followed by $0.03 \%$ (w/v) LMNG, $0.01 \%(w / v)$ glyco-diosgenin (GDN, Anatrace) and $0.008 \%$ (w/v) CHS for 20 column volumes washing. His-tagged TEV protease was then added and incubated with resin at $4{ }^{\circ} \mathrm{C}$ overnight. The flow-through was collected and concentrated with an Amicon Ultra Centrifugal Filter (MWCO $100 \mathrm{kDa}$ ) and loaded onto a Superdex 200 10/300 GL column (GE Healthcare) with running buffer containing $20 \mathrm{mM}$ HEPES $\mathrm{pH} 7.4,100 \mathrm{mM} \mathrm{NaCl}, 2 \mathrm{mM} \mathrm{MgCl}, 100 \mu \mathrm{M}$ TCEP, $40 \mu \mathrm{M}$ peptide, $0.00075 \%$ (w/v) LMNG, $0.00025 \%(\mathrm{w} / \mathrm{v})$ GDN and $0.0002 \%(\mathrm{w} / \mathrm{v})$ CHS. The fractions of monomeric protein complex were collected and concentrated with an Amicon Ultra Centrifugal Filter (MWCO $100 \mathrm{kDa}$ ) by $30-50$-fold for sample preparation and detection by cryo-EM.
Cryo-EM grid preparation and data collection. For cryo-EM grid preparation of the bradykinin-B2R- $\mathrm{G}_{\mathrm{q}}$ complex, $3 \mu \mathrm{l}$ of purified protein $\left(21 \mathrm{mg} \mathrm{ml}^{-1}\right)$ was loaded onto a glow-discharged holey carbon grid (Quantifoil, Au300 R1.2/1.3) using a Vitrobot chamber (FEI Vitrobot Mark IV). Cryo-EM images were collected by a FEI Titan Krios at $300 \mathrm{kV}$ accelerating voltage equipped with a Gatan K3 Summit direct electron detector at the Center of Cryo-Electron Microscopy Research Center, Shanghai Institute of Materia Medica, Chinese Academy of Sciences. Micrographs were recorded with a pixel size of $1.045 \AA$. In total 3,437 movies were obtained at a dose of 80 electrons per $\AA^{2}$ for 36 frames.

For the des-Arg ${ }^{10}$-kallidin-B1R-G $\mathrm{G}_{\mathrm{q}}$ complex, $7.9 \mathrm{mg} \mathrm{ml}^{-1}$ of purified protein was used for cryo-EM grid preparation, as described above. Cryo-EM images were collected by Titan Krios G3i at $300 \mathrm{kV}$ accelerating voltage at Shuimu BioSciences. The microscope was operated in super-resolution counting mode at a pixel size of $0.54 \AA$, and a total of 2,779 movies were obtained at a dose of 61.8 electrons per $\AA^{2}$ for 32 frames.

Cryo-EM data processing three-dimensional reconstruction. Cryo-EM data of the des-Arg ${ }^{10}$-kallidin-B1R- $\mathrm{G}_{\mathrm{q}}$ and bradykinin-B2R- $\mathrm{G}_{\mathrm{q}}$ complexes were processed using RELION v.3.1.0 (ref. ${ }^{40}$ ). The detailed flowchart of data processing is shown in Extended Data Figs. 1b-d and 2b-d. Dose-fractionated image stacks for both complexes were subjected to dose-weighting and beam-induced motion correction using MotionCor v. 2.1 (ref. ${ }^{41}$ ). Contrast transfer function (CTF) was carried using CTFFIND v.4.1 (ref. ${ }^{42}$ ). The subsequent particle selection, two-dimensional (2D) and three-dimensional (3D) classifications for the des- $\mathrm{Arg}^{10}$-kallidin-B1R-G $\mathrm{G}_{\mathrm{q}}$ and bradykinin-B2R- $\mathrm{G}_{\mathrm{q}}$ complexes were performed on a binned dataset with a pixel size of $1.08 \AA$ and $1.045 \AA$, respectively.

For the des-Arg ${ }^{10}$-kallidin-B1R-G G $_{\mathrm{q}}$ complex, autopicking yielded 3,681,755 particle projections that were subjected to two rounds of reference-free $2 \mathrm{D}$ classifications to extract particles in well-defined classes. The extracted 2,486,616 particles were used to generate a $3 \mathrm{D}$ initial model for further processing. With the initial model, two rounds of maximum-likelihood-based 3D classifications were carried out, resulting in one well-defined subset with 796,080 particle projections. A further two rounds of 3D classifications were conducted with the mask on the receptor and $\mathrm{G}$ protein, respectively, in which 633,636 particles were subjected to $3 \mathrm{D}$ autorefinement, three rounds of CTF refinement and Bayesian polishing. A map with an indicated global resolution of $3.0 \AA$ at a Fourier shell correlation (FSC) of 0.143 was generated from the final $3 \mathrm{D}$ refinement, and subsequently post-processed by DeepEMhancer ${ }^{43}$.

For the bradykinin-B2R- $\mathrm{G}_{\mathrm{q}}$ complex, autopicking yielded 3,460,328 particle projections that were subjected to two rounds of reference-free $2 \mathrm{D}$ classifications, producing 2,623,863 particle projections for further processing. With the initial model, three rounds of maximum-likelihood-based 3D classifications were carried out, resulting in one well-defined subset with 664,416 particle projections. A map with an indicated global resolution of $2.9 \AA$ at a FSC of 0.143 was generated from the final 3D refinement, and subsequently post-processed by DeepEMhancer. Local resolutions for density maps of the des- Arg $^{10}$-kallidin-B1R- $G_{q}$ and bradykinin-B2R- $\mathrm{G}_{\mathrm{q}}$ complexes were determined using the ResMap package with half maps as input maps ${ }^{44}$.

Model building and refinement. Homology models of active-state B1R and B2R were built by SWISS-MODEL ${ }^{45}$ using AT1R (PDB 6OS0) ${ }^{31}$ and AT2R (PDB 6JOD) ${ }^{46}$ as template models for the receptors, respectively. The $\mathrm{G}_{\mathrm{q}}$ heterotrimer was built on the basis of the corresponding $\mathrm{G}$ protein of the $5-\mathrm{HT}_{2 \mathrm{~A}} \mathrm{R}-\mathrm{G}_{\mathrm{q}}$ (PDB $6 \mathrm{WHA})^{25}$ complex as a template. All models were fitted into the cryo-EM density map using Chimera ${ }^{47}$ followed by a manual adjustment in $\operatorname{Coot}^{48}$. The generated final model was refined in Phenix ${ }^{49}$. The final refinement statistics are provided in Table 1. Structural figures were prepared with Chimera, ChimeraX ${ }^{50}$ or PyMOL (https://pymol.org/2/).

Calcium mobilization assay. HEK 293T cells were transiently transfected with wild-type or mutant bradykinin receptors after being seeded into 96 -well plates at a density of 50,000 cells per well and incubated for $24 \mathrm{~h}$ at $37^{\circ} \mathrm{C}$ in $5 \%$ $\mathrm{CO}_{2}$. The cells, from which medium had been removed, were reacted with $2 \mathrm{mM}$ Fluo-4-AM in HBSS and $20 \mathrm{mM}$ HEPES supplemented with $2.5 \mathrm{mM}$ probenecid for $45 \mathrm{~min}$ at $37^{\circ} \mathrm{C}$ in $5 \% \mathrm{CO}_{2}$. Different concentrations of bradykinin or des-Arg ${ }^{10}$-kallidin were added, followed by an analysis of intracellular calcium mobilization on a FLIPR instrument (Molecular Devices) with excitation at $470-495 \mathrm{~nm}$ and emission at $515-575 \mathrm{~nm}$. Data were normalized to the baseline response of the ligand.

Statistics. All functional study data were analyzed using GraphPad Prism v.8.0 (Graphpad Software) and shown as mean \pm s.e.m. from at least three independent experiments. Concentration-response curves were evaluated with a three-parameter logistic equation. The significance was determined with two-tailed Student's $t$-test, and $P<0.05$ was considered statistically significant.

Reporting Summary. Further information on research design is available in the Nature Research Reporting Summary linked to this article. 


\section{Data availability}

Materials are available from the corresponding authors upon reasonable request. Density maps and structure coordinates have been deposited in the Electron Microscopy Data Bank (EMDB) and the Protein Data Bank (PDB) with accession codes EMD-31145 and PDB 7EIB for the des- Arg $^{10}$-kallidin-B1R- $\mathrm{G}_{\mathrm{q}}$ complex; EMD-31429 and PDB 7F2O for the bradykinin-B2R- $\mathrm{G}_{\mathrm{q}}$ complex. Source data are provided with this paper.

\section{References}

36. Chun, E. et al. Fusion partner toolchest for the stabilization and crystallization of G protein-coupled receptors. Structure 20, 967-976 (2012).

37. Liu, P. et al. The structural basis of the dominant negative phenotype of the $\mathrm{G} \alpha_{i 1} \beta_{1} \gamma_{2}$ G203A/A326S heterotrimer. Acta Pharmacol. Sin. 37, 1259-1272 (2016).

38. Kang, Y. et al. Cryo-EM structure of human rhodopsin bound to an inhibitory G protein. Nature 558, 553-558 (2018).

39. Rasmussen, S. G. et al. Crystal structure of the $\beta_{2}$ adrenergic receptor-Gs protein complex. Nature 477, 549-555 (2011).

40. Zivanov, J., Nakane, T. \& Scheres, S. H. W. Estimation of high-order aberrations and anisotropic magnification from cryo-EM data sets in RELION-3.1. IUCrJ 7, 253-267 (2020).

41. Zheng, S. Q. et al. MotionCor2: anisotropic correction of beam-induced motion for improved cryo-electron microscopy. Nat. Methods 14, 331-332 (2017).

42. Rohou, A. \& Grigorieff, N. CTFFIND4: fast and accurate defocus estimation from electron micrographs. J. Struct. Biol. 192, 216-221 (2015).

43. Sánchez-García, R. et al. DeepEMhacer: a deep learning solution for cryo-EM volume post-processing. Commun. Biol. 4, 874 (2021).

44. Kucukelbir, A., Sigworth, F. J. \& Tagare, H. D. Quantifying the local resolution of cryo-EM density maps. Nat. Methods 11, 63-65 (2014).

45. Waterhouse, A. et al. SWISS-MODEL: homology modelling of protein structures and complexes. Nucleic Acids Res. 46, W296-W303 (2018)

46. Asada, H. et al. The crystal structure of angiotensin II type 2 receptor with endogenous peptide hormone. Structure 28, 418-425.e4 (2020).

47. Pettersen, E. F. et al. UCSF Chimera-a visualization system for exploratory research and analysis. J. Comput. Chem. 25, 1605-1612 (2004).

48. Emsley, P. \& Cowtan, K. Coot: model-building tools for molecular graphics. Acta Crystallogr. D Biol. Crystallogr. 60, 2126-2132 (2004).

49. Adams, P. D. et al. PHENIX: a comprehensive Python-based system for macromolecular structure solution. Acta Crystallogr. D Biol. Crystallogr. 66, 213-221 (2010).

50. Pettersen, E. F. et al. UCSF ChimeraX: structure visualization for researchers, educators, and developers. Protein Sci. 30, 70-82 (2021).

\section{Acknowledgements}

The cryo-EM data of the bradykinin-B2R- $\mathrm{G}_{q}$ complex were collected at the Cryo-Electron Microscopy Research Center, Shanghai Institute of Material Medica. Cryo-EM data collection of the des- Arg $^{10}$-kallidin-B1R- $\mathrm{G}_{\mathrm{q}}$ complex was carried out at Shuimu BioSciences. We thank all the staff at these two cryo-EM facilities for their technical support. This work was partially supported by the Ministry of Science and Technology (China) grants 2018YFA0507002 (H.E.X.) and 2018YFA0507000 (M.-W.W.); National Natural Science Foundation of China 31770796 (Y.J.), 81872915 (M.-W.W.), 82073904 (M.-W.W.), 81773792 (D.Y.) and 81973373 (D.Y.); National Science and Technology Major Project of China-Key New Drug Creation and Manufacturing Program 2018ZX09711002-002-002 (Y.J.), 2018ZX09735-001 (M.-W.W.) and 2018ZX09711002-002-005 (D.Y.); the Shanghai Municipal Science and Technology Commission Major Project 2019SHZDZX02 (H.E.X.); the CAS Strategic Priority Research Program XDB37030103 (H.E.X.); Novo Nordisk-CAS Research Fund grant NNCAS-2017-1-CC (D.Y.); the Young Innovator Association of CAS 2021278 (W.Y.); and China Postdoctoral Science Foundation 2021T140689 (F.Z.).

\section{Author contributions}

Y.-L.Y. screened the expression constructs, optimized the bradykinin receptor- $\mathrm{G}_{\mathrm{q}}$ protein complexes, prepared the protein samples for final structure determination and participated in cryo-EM grid inspection, data collection and model building. C.Y. and J.W. designed the mutations and executed the functional studies. F.Z. built and refined the structure models. M.-W.W. and D.Y. supervised functional assay development and data analysis. W.Y. designed $\mathrm{G}_{\mathrm{q}}$ protein constructs and prepared samples for the cryo-EM. H.E.X. and Y.J. conceived and supervised the project and initiated collaborations with M.-W.W. Y.J. and Y.-L.Y. prepared the figures and drafted the manuscript. Y.J., H.E.X. and M.-W.W wrote the manuscript with input from all authors.

\section{Competing interests}

The authors declare no competing interests.

\section{Additional information}

Extended data is available for this paper at https://doi.org/10.1038/s41594-021-00645-y.

Supplementary information The online version contains supplementary material available at https://doi.org/10.1038/s41594-021-00645-y.

Correspondence and requests for materials should be addressed to Wanchao Yin, Ming-Wei Wang, H. Eric Xu or Yi Jiang.

Peer review information Nature Structural \& Molecular Biology thanks Sjors Scheres and the other, anonymous, reviewer(s) for their contribution to the peer review of this work. Peer reviewer reports are available. Florian Ullrich was the primary editor on this article and managed its editorial process and peer review in collaboration with the rest of the editorial team.

Reprints and permissions information is available at www.nature.com/reprints. 
a

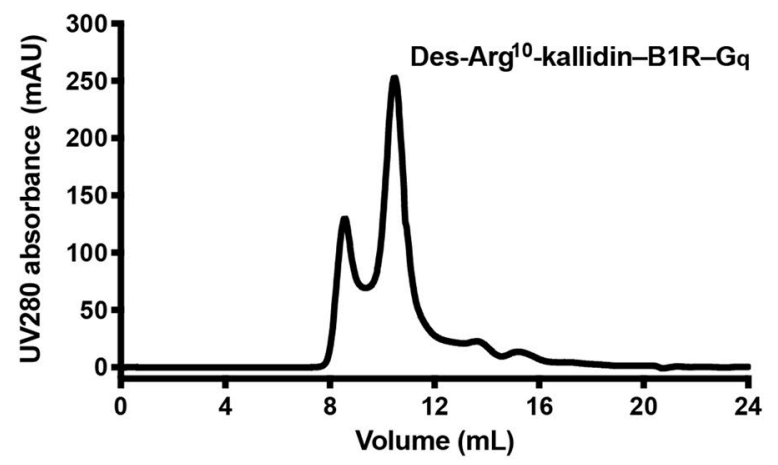

b

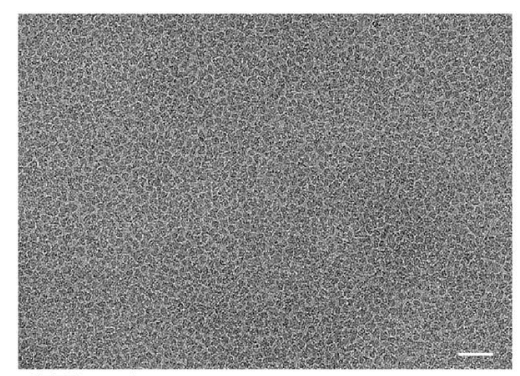

2779 movies

Motion correction

CTF correction - 2,651 movies

Autopicking - 3,681,755 particles

$2 D$ classification -2 rounds

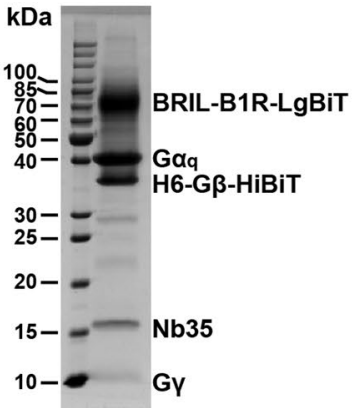

d

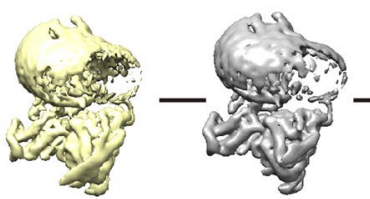

$54.3 \%$

$32.0 \%$

C
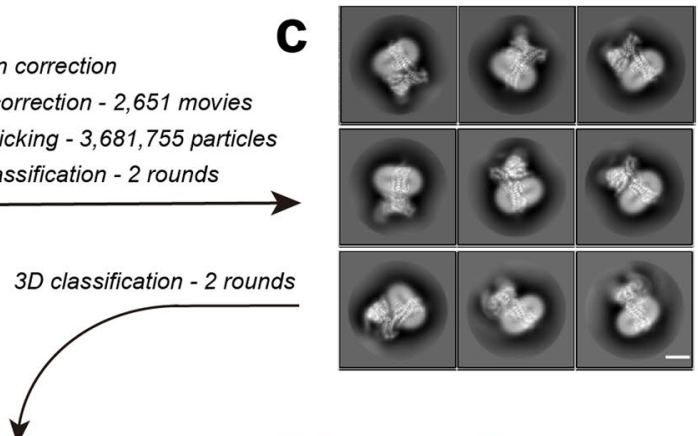

$3 D$ classification with mask on receptor

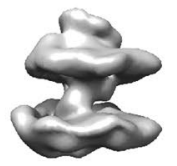

$1.4 \%$

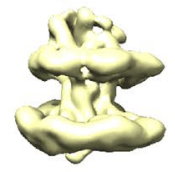

$6.0 \%$

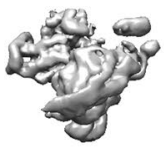

$36.7 \%$

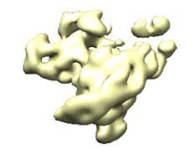

$1.5 \%$

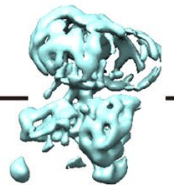

$4.7 \%$

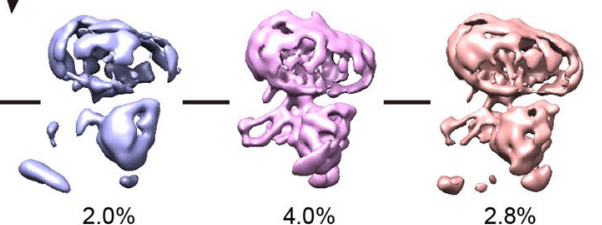

$2.0 \%$

$4.0 \%$

$2.8 \%$
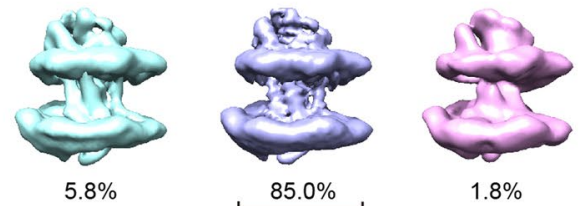

$1.8 \%$
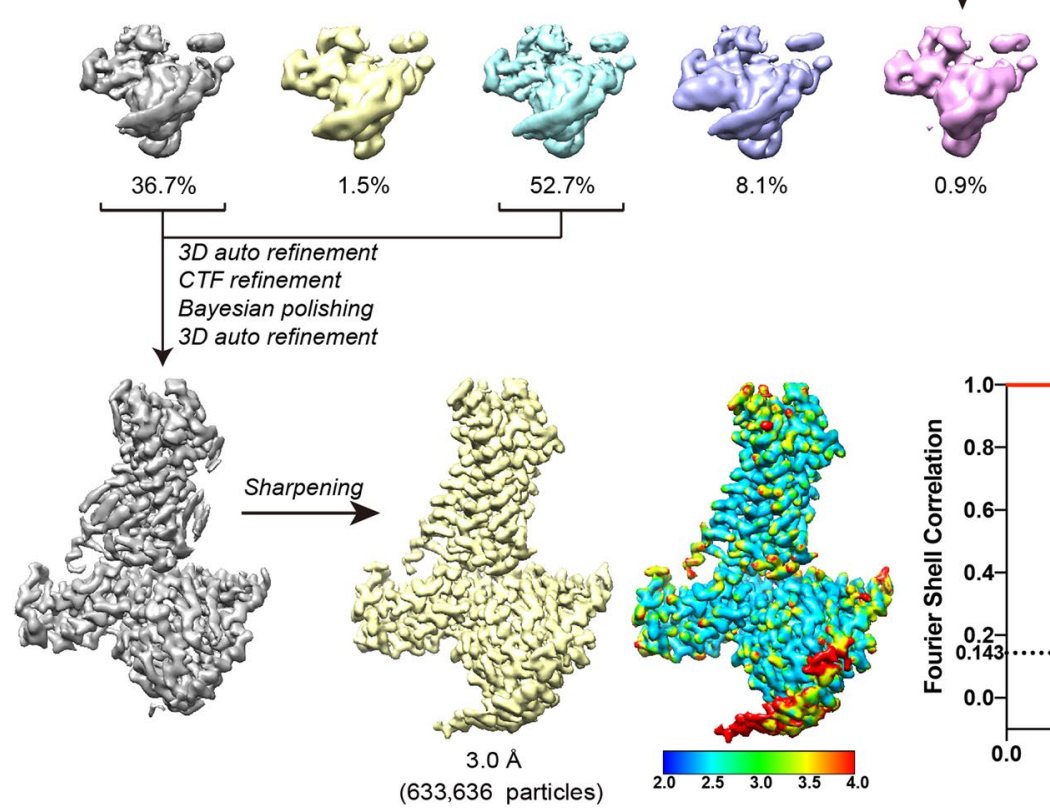

(1)

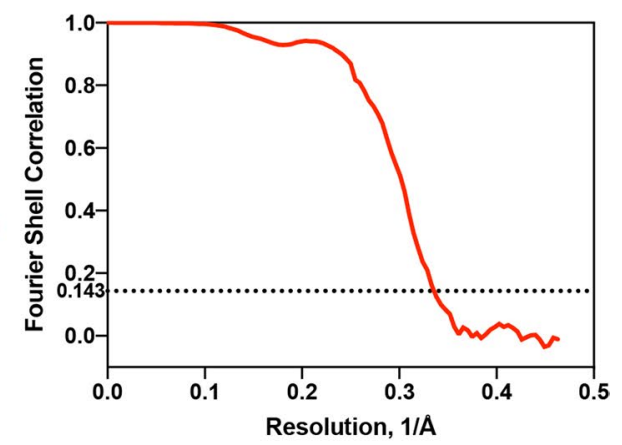

Extended Data Fig. 1 | See next page for caption. 
Extended Data Fig. 1 | Des-Arg ${ }^{10}$-kallidin-B1R-G G $_{q}$ complex purification and cryo-EM data processing. a, Representative size-exclusion chromatography

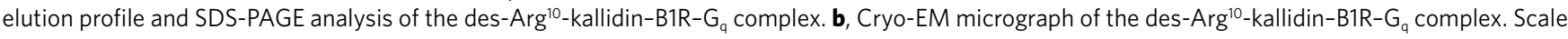
bar, $50 \mathrm{~nm}$. The complex sample preparation (a) and data collection (b) was performed once. c, Representative 2D average classes of the des-Arg ${ }^{10}-$ kallidin-B1R-G ${ }_{q}$ complex. Scale bar, $5 \mathrm{~nm}$. d, Flowchart of cryo-EM data processing. Source data for a are available online. 
a
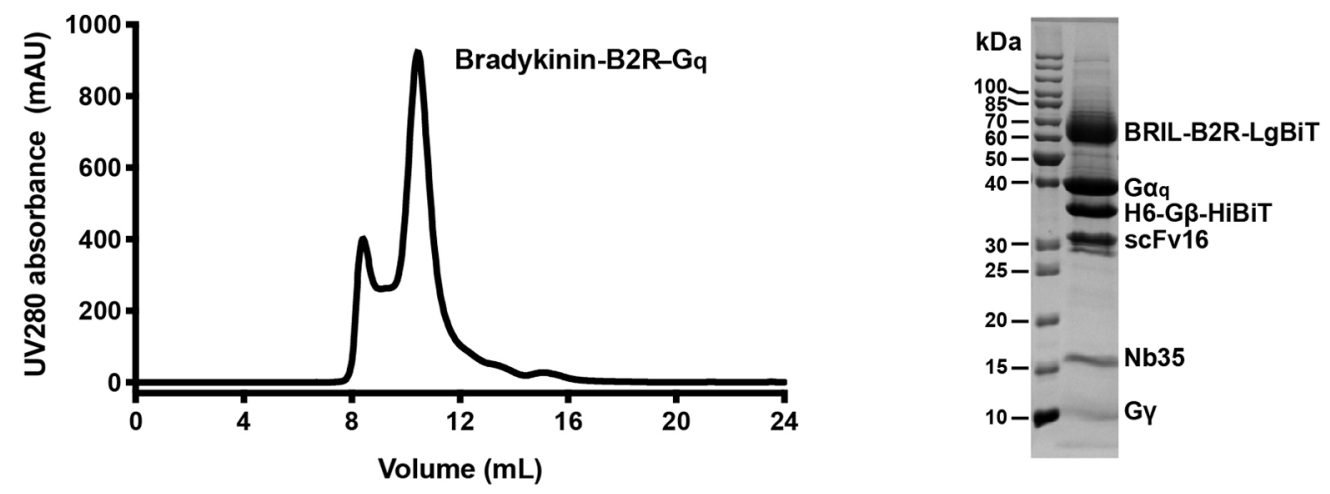

b

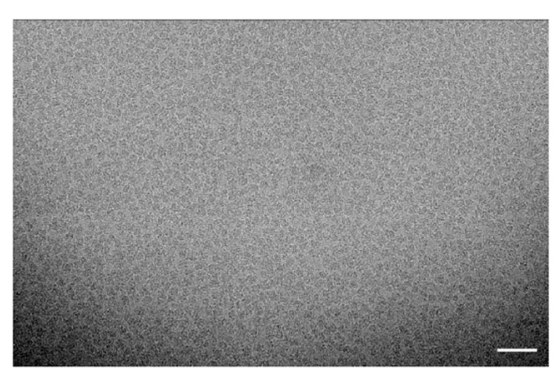

Motion correction

CTF correction - 2,959 movies Autopicking - 3,460,328 particles $2 D$ classification - 2 rounds
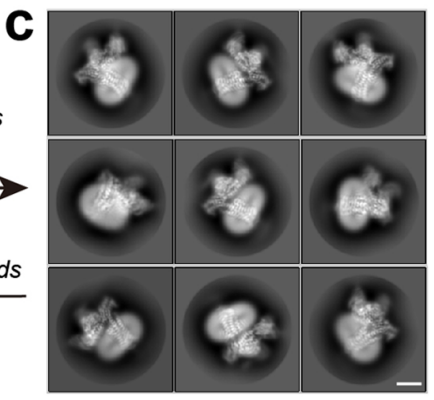

d 3437 movies

$3 D$ classification - 3 rounds
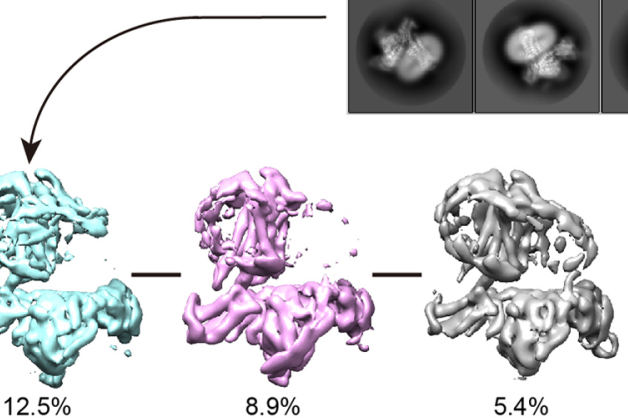

$3 D$ auto refinement

CTF refinement

Bayesian polishing

$3 D$ auto refinement
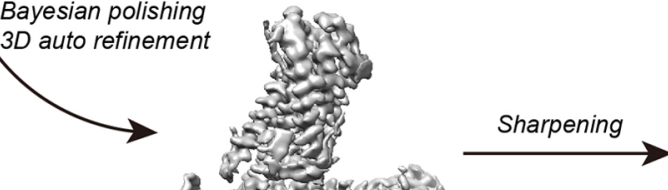

e

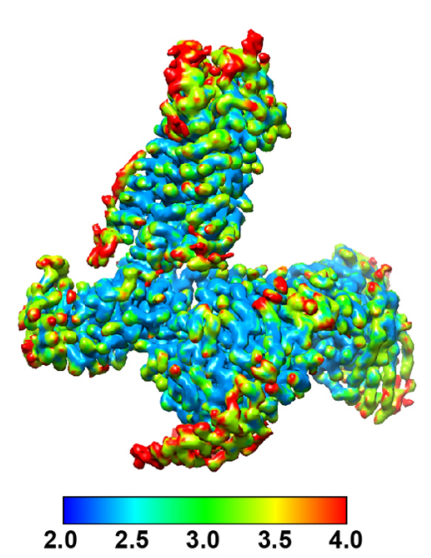

f

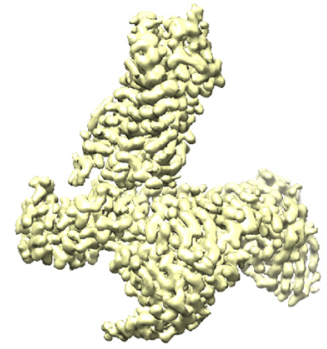

$2.9 \AA$

$(664,416$ particles)

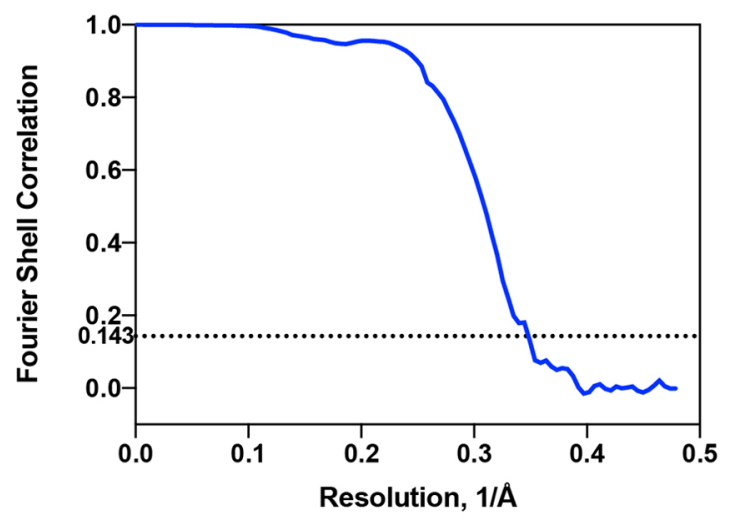

Extended Data Fig. 2 | See next page for caption. 
Extended Data Fig. 2 | Bradykinin-B2R-G complex purification and cryo-EM data processing. a, Representative size-exclusion chromatography elution profile and SDS-PAGE analysis of the bradykinin-B2R-G complex. b, Cryo-EM micrograph of the bradykinin-B2R- $\mathrm{G}_{\mathrm{q}}$ complex. Scale bar, $50 \mathrm{~nm}$. The complex sample preparation (a) and data collection (b) was performed once. c, Representative 2D average classes of the bradykinin-B2R- $\mathrm{G}_{\mathrm{q}}$ complex. Scale bar, $5 \mathrm{~nm}$. d, Flowchart of cryo-EM data processing. e, Cryo-EM map of the bradykinin-B2R-G complex, colored by local resolution ( $\AA$ ) calculated using Resmap package. f, 'Gold-standard' FSC curves. Source data for a are available online. 


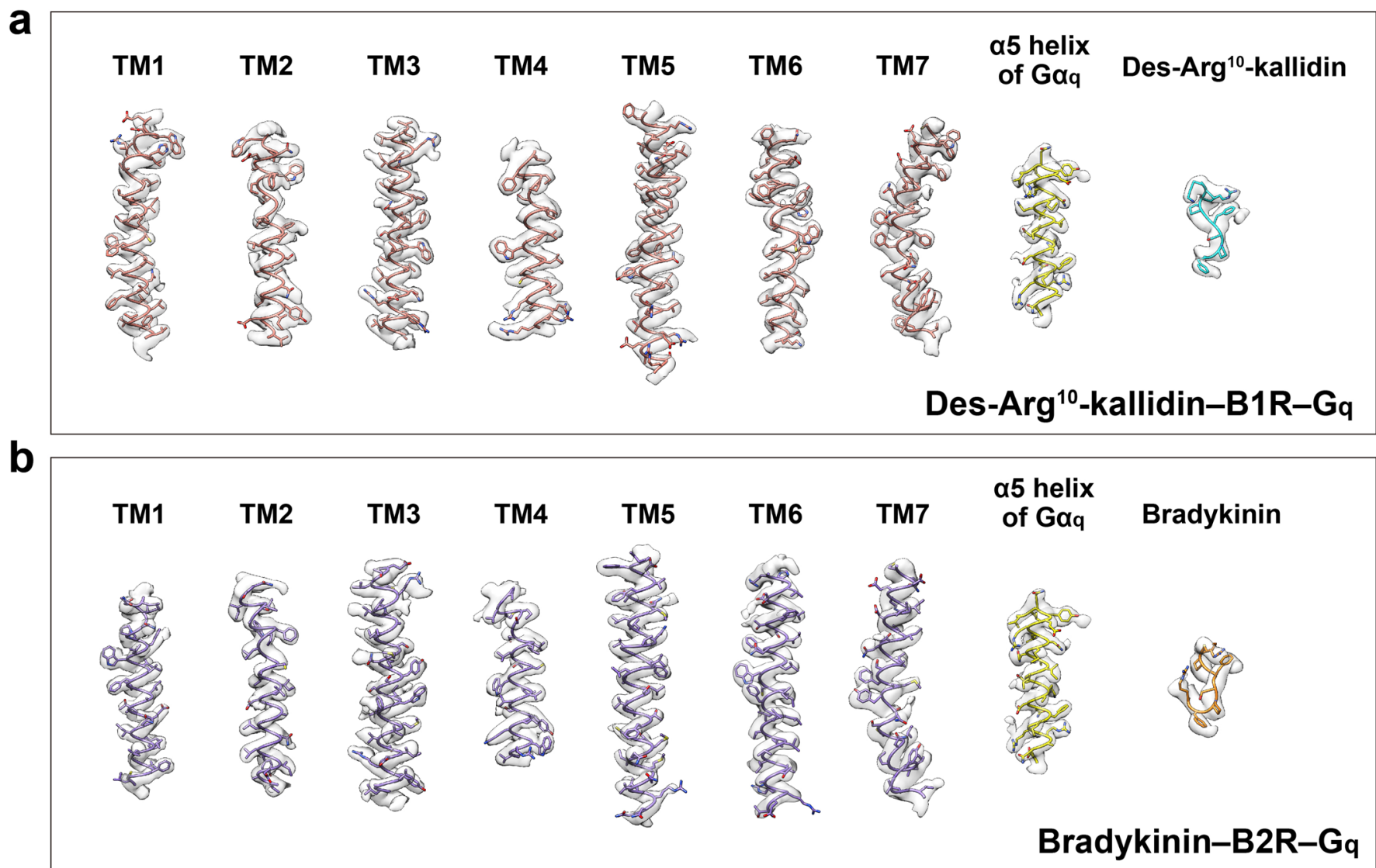

Extended Data Fig. 3 | Cryo-EM density maps of the des-Arg ${ }^{10}-k_{k}$ allidin-B1R-G and bradykinin-B2R-G $\mathbf{G}_{\mathrm{q}}$ complex. $\mathbf{a}$, Cryo-EM density maps of the seven transmembrane (TM) helices of B1R, $\alpha 5$ helix of $G \alpha_{q}$, and des-Arg ${ }^{10}$-kallidin. $\mathbf{b}$, Cryo-EM density maps of the seven TM helices of B2R, $\alpha 5$ helix of $G \alpha_{q}$, and bradykinin. 


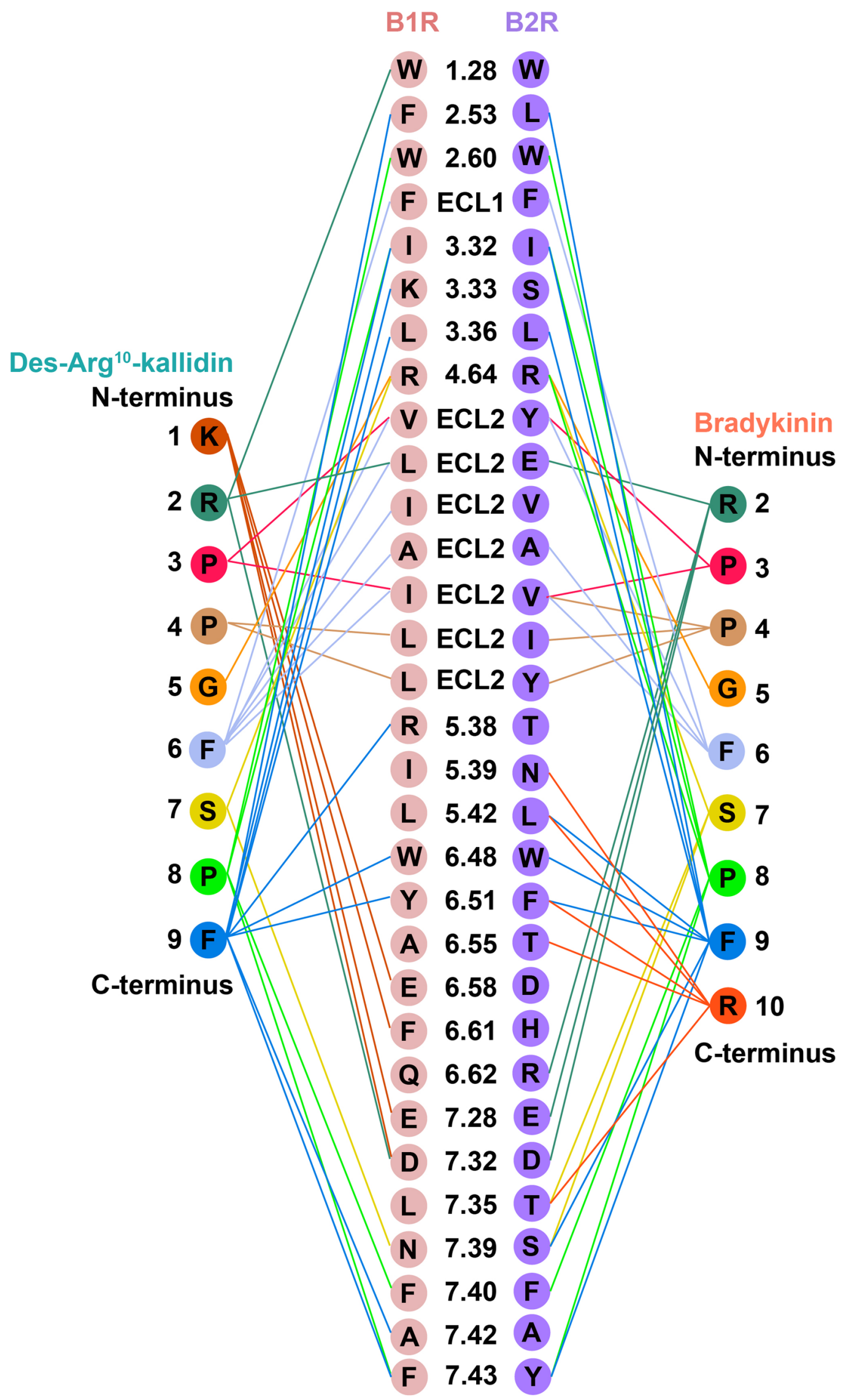

Extended Data Fig. 4 | Representative interaction network of des-Arg ${ }^{10}$-kallidin bound to B1R and bradykinin bound to B2R. Amino acids in des-Arg ${ }^{10}$-kallidin and bradykinin, as well as residues in binding pocket of B1R and B2R, are displayed as circled one-letter codes. Lines show interactions between peptides and bradykinin receptor subtypes. Colors are shown as indicated. 
a

TM1,2,3,4

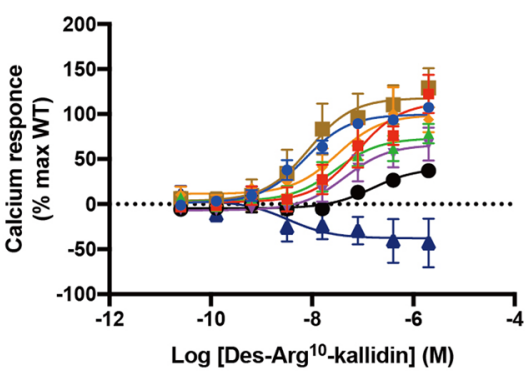

b

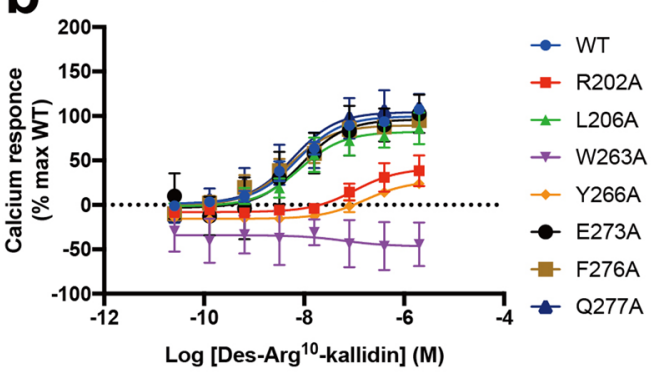

C

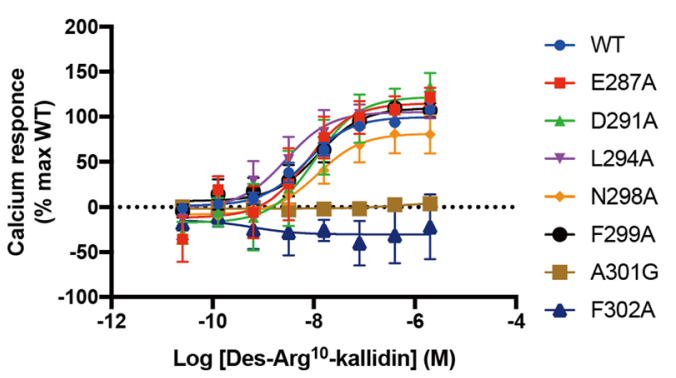

d

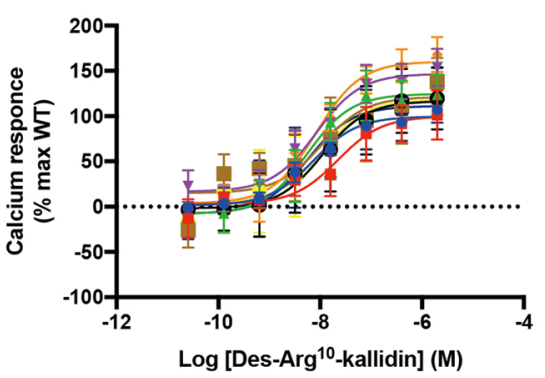

i

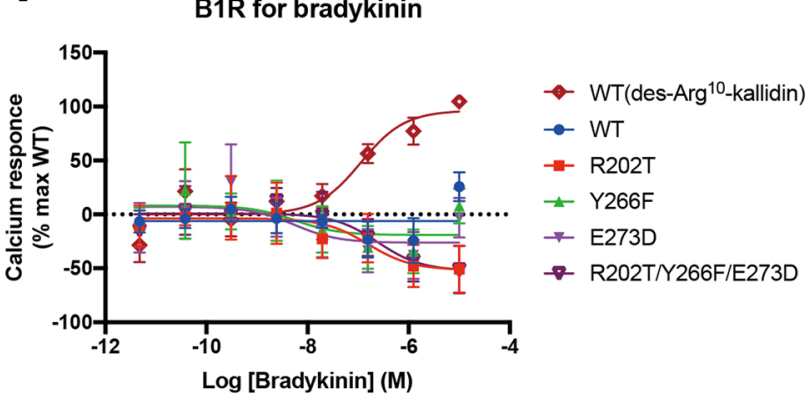

e

TM2,3,4

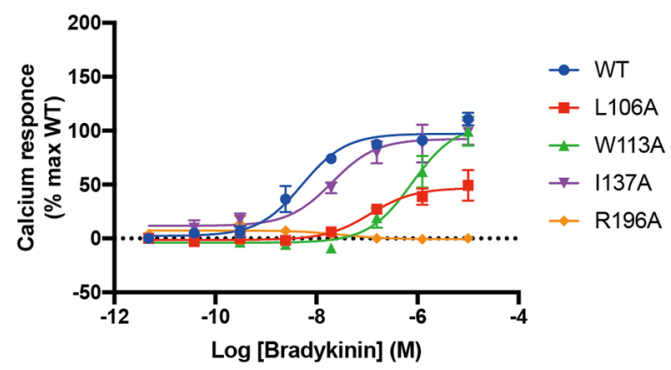

f

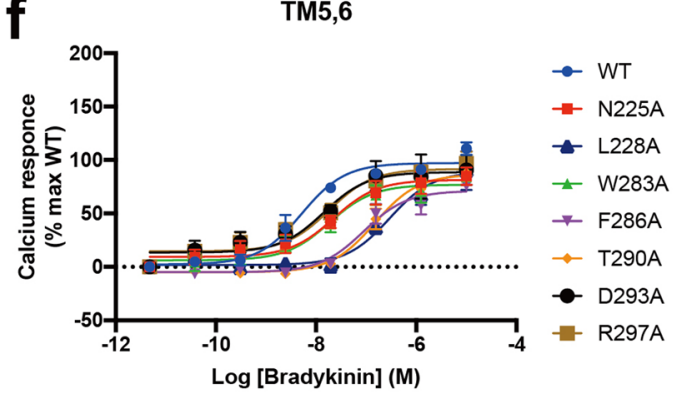

9

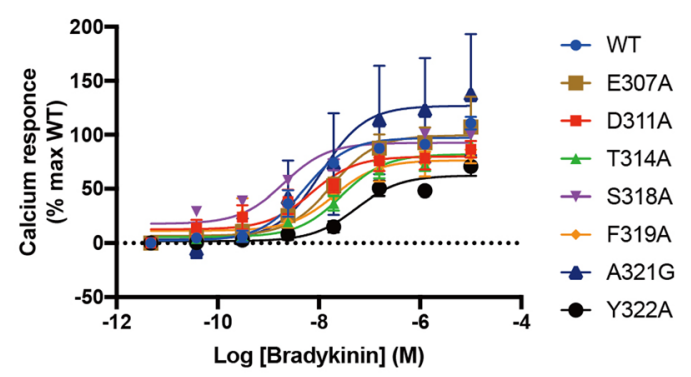

h

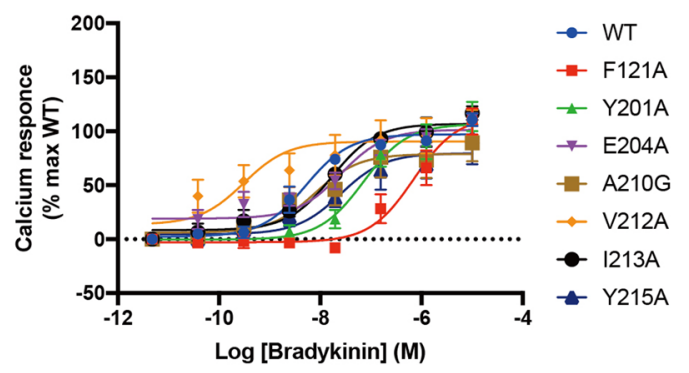

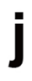

B2R for des-Arg ${ }^{10}$-kallidin

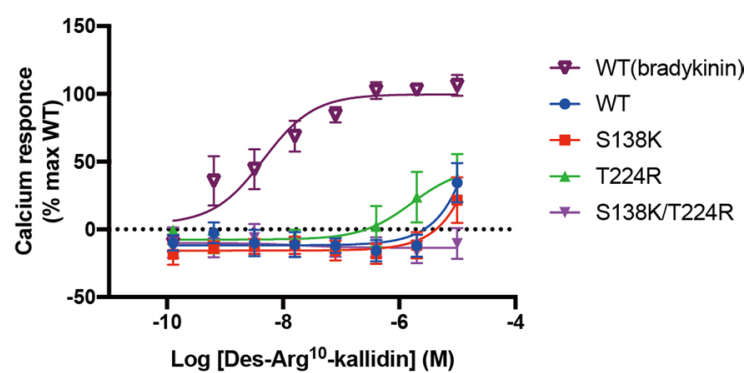

Extended Data Fig. 5 | Calcium response curves of B1R and B2R. Effects of B1R mutations (a-d) or B2R mutations (e-h) on des-Arg ${ }^{10}-k_{a l l i d i n-}$ or bradykinin-induced calcium mobiliazation. $\mathbf{i}, \mathbf{j}$, Effects of des-Arg ${ }^{10}$-kallidin and bradykinin on bradykinin receptors with swapped mutations. Each data point presents mean \pm S.E.M. of three independent experiments. WT, wild-type. Source data are available online. 
a

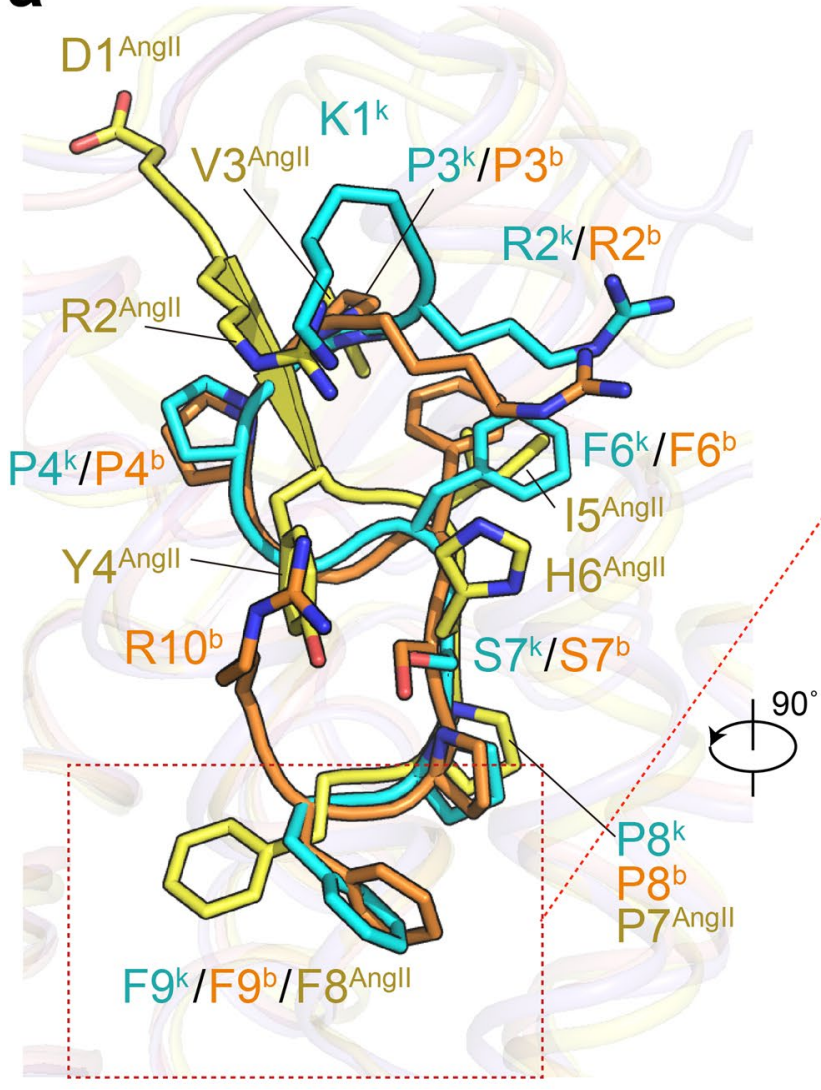

b

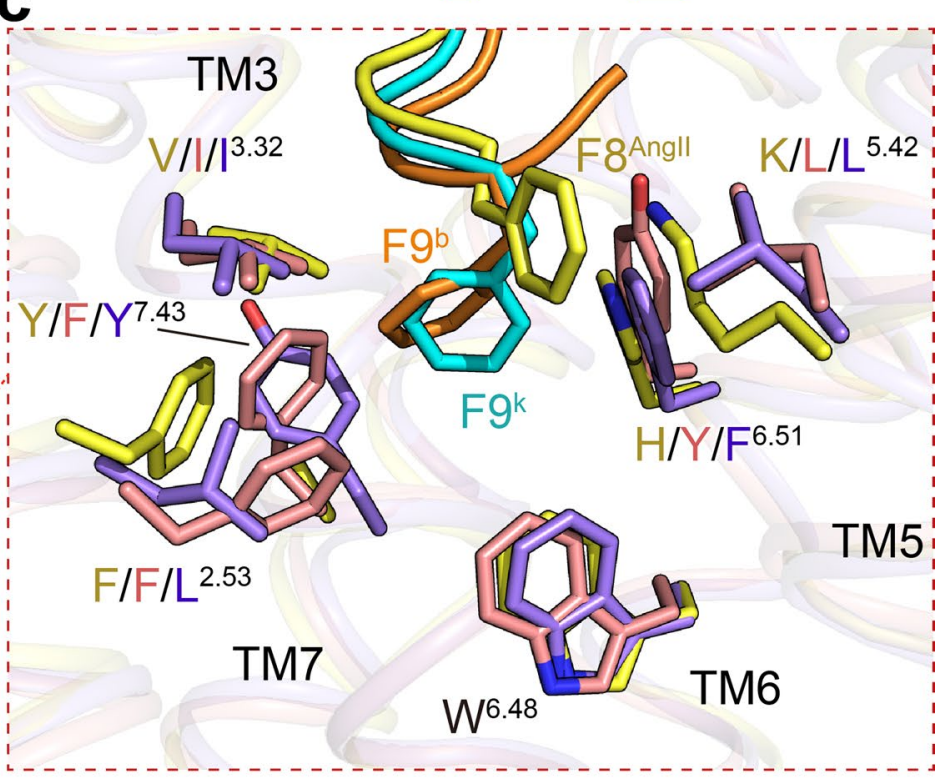

Des-Arg ${ }^{10}-k a l l i d i n / B 1 R$

Bradykinin / B2R

Ang II / AT1R

Extended Data Fig. 6 | Conformational comparison of des-Arg ${ }^{10}$-kallidin and bradykinin with angiotensin II. a,b, The conformational comparison (a) and sequence alignment (b) of des-Arg ${ }^{10}$-kallidin, bradykinin, and angiotensin II (AngII). c, A structural comparison of conserved phenylalanine in peptides and their surrounding residues in corresponding receptors. Peptides and receptors are colored as indicated. Ang II-AT1R complex (PDB 6OSO). 
a

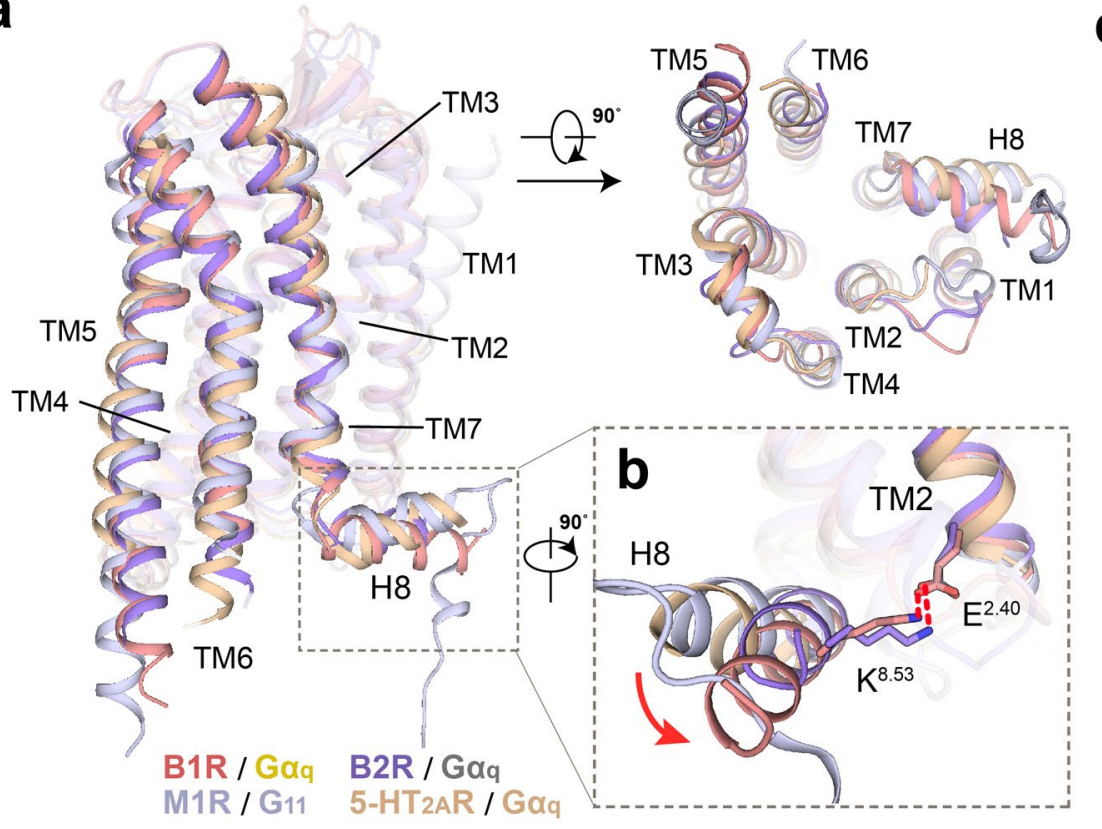

C

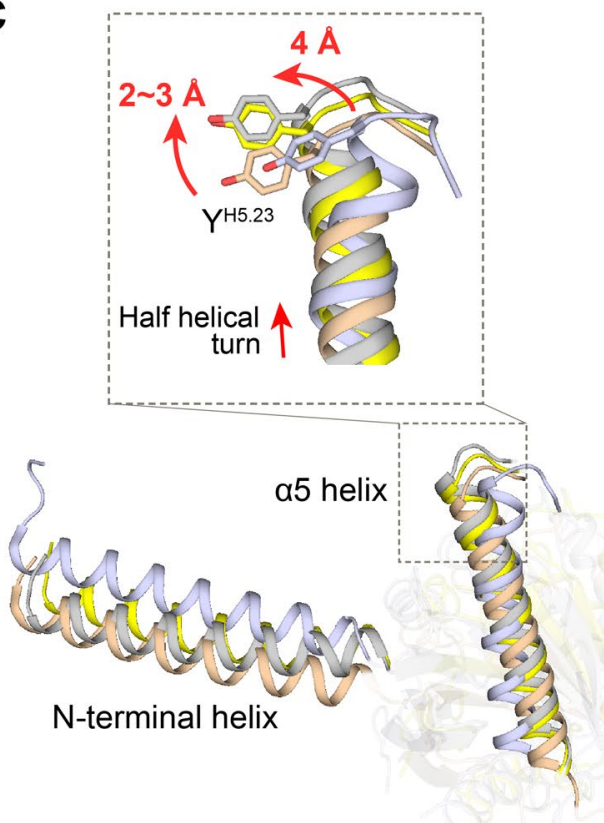

Extended Data Fig. 7 | $G_{q}$ protein-coupling of bradykinin receptors. a, An overall conformational comparison of two $\mathrm{G}_{\mathrm{q}}$-coupled bradykinin receptors with $\mathrm{G}_{\mathrm{q}}$-coupled 5-HT $\mathrm{HT}_{2 \mathrm{~A}} \mathrm{R}$ (PDB 6WHA) and $\mathrm{G}_{11}$-coupled M1R (PDB 6OIJ). b, A conformational comparison of the helix 8 of four $\mathrm{G}_{\mathrm{q} / 11}$-coupled receptors. Movement directions of helix 8 in two bradykinin receptors relative to that of $5-\mathrm{HT}_{2 \mathrm{~A}} \mathrm{R}$ and M1R are indicated as red arrows. $\mathrm{H}$-bonds are shown as red dashed lines. c, A structural comparison of $\alpha 5$ helix and $\alpha \mathrm{N}$ of $G \alpha_{\alpha / 11}$ among four $\mathrm{G}_{\mathrm{q} / 11}$-coupled receptor complexes. Red arrows indicate the movements of $\alpha 5$ helix of $G \alpha_{q}$ from the bradykinin receptor- $G_{q}$ complexes compared to $5-H T_{2 A} R-G_{q}$ or $M 1 R-G_{11}$ complexes. The complex structures were aligned by the receptors. 

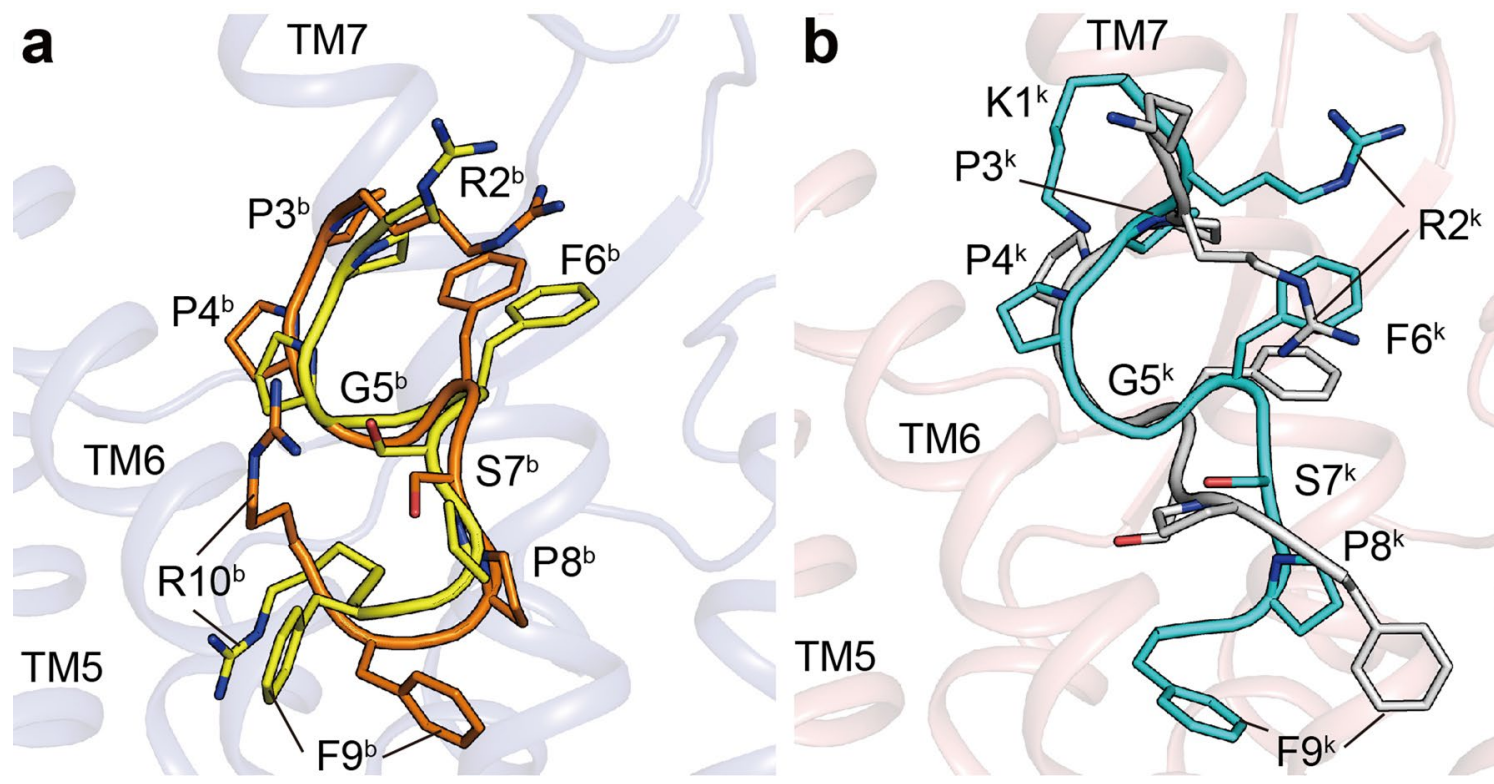

Extended Data Fig. 8 | Conformational comparison of kinins in structure and in NMR model. a, Conformational superposition of bradykinin in B2R structure (orange) and in NMR model (yellow, PDB 6F3V). b. Conformational superposition of des-Arg ${ }^{10}$-kallidin in B1R structure (cyan) and in NMR model (silver, PDB 6F3Y). Kinins are shown as cartoons, and side chains are displayed as sticks. 


\section{nature research}

\section{Reporting Summary}

Nature Research wishes to improve the reproducibility of the work that we publish. This form provides structure for consistency and transparency in reporting. For further information on Nature Research policies, see our Editorial Policies and the Editorial Policy Checklist.

\section{Statistics}

For all statistical analyses, confirm that the following items are present in the figure legend, table legend, main text, or Methods section.

$\mathrm{n} / \mathrm{a}$ Confirmed

\The exact sample size $(n)$ for each experimental group/condition, given as a discrete number and unit of measurement

Х

A statement on whether measurements were taken from distinct samples or whether the same sample was measured repeatedly

The statistical test(s) used AND whether they are one- or two-sided

Only common tests should be described solely by name; describe more complex techniques in the Methods section.

Х $\square$ A description of all covariates tested

Х $\square$ A description of any assumptions or corrections, such as tests of normality and adjustment for multiple comparisons

$\triangle$ A full description of the statistical parameters including central tendency (e.g. means) or other basic estimates (e.g. regression coefficient)

AND variation (e.g. standard deviation) or associated estimates of uncertainty (e.g. confidence intervals)

$\varnothing$ For null hypothesis testing, the test statistic (e.g. $F, t, r$ ) with confidence intervals, effect sizes, degrees of freedom and $P$ value noted

Give $P$ values as exact values whenever suitable.

Х $\square$ For Bayesian analysis, information on the choice of priors and Markov chain Monte Carlo settings

Х $\square$ For hierarchical and complex designs, identification of the appropriate level for tests and full reporting of outcomes

Х $\square$ Estimates of effect sizes (e.g. Cohen's $d$, Pearson's $r$ ), indicating how they were calculated

Our web collection on statistics for biologists contains articles on many of the points above.

\section{Software and code}

Policy information about availability of computer code

Data collection Automated data collection on the Titan Krios using serialEM 3.7.11.

Data analysis RELION-3.1.0, MotionCor2.1, CTFFIND-4.1, Resmap-1.1.4, Chimera-1.14, COOT-0.8.9, Phenix1.18.2-3874, ChimeraX-1.0, PyMOL-2.4.1, Graphpad 8.

For manuscripts utilizing custom algorithms or software that are central to the research but not yet described in published literature, software must be made available to editors and

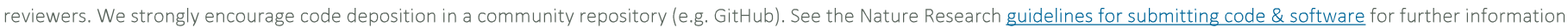

\section{Data}

Policy information about availability of data

All manuscripts must include a data availability statement. This statement should provide the following information, where applicable:

- Accession codes, unique identifiers, or web links for publicly available datasets

- A list of figures that have associated raw data

- A description of any restrictions on data availability

Materials are available from the corresponding authors upon reasonable request. Density maps and structure coordinates have been deposited in the Electron Microscopy Data Bank (EMDB) and the Protein Data Bank (PDB) with accession codes EMD-31145 and PDB 7EIB for the des-Arg10-kallidin-B1R-Gq complex; EMD-31429 and PDB 7F2O for the bradykinin-B2R-Gq complex. Source data are provided with this paper. 
Please select the one below that is the best fit for your research. If you are not sure, read the appropriate sections before making your selection.

\ Life sciences

Behavioural \& social sciences

Ecological, evolutionary \& environmental sciences

For a reference copy of the document with all sections, see nature.com/documents/nr-reporting-summary-flat.pdf

\section{Life sciences study design}

All studies must disclose on these points even when the disclosure is negative.

$\begin{array}{ll}\text { Sample size } & \begin{array}{l}\text { For cryo-EM data, images were collected until the resolution and 3D reconstruction converges. For all the functional assay, no statistical } \\ \text { approaches were used to predetermine the sample size. We use sample size at least of three independent experiments, commonly exploited }\end{array}\end{array}$ by researchers in this field.

Data exclusions No data were excluded from the analysis.

Replication Experimental findings were reliably reproduced within one month.

Randomization Randomization was not relevant to this study, as the data were collected automatically and did not involve choosing.

Blinding Investigators were not blinded during data acquisition and analysis because it is not a common procedure for the method used.

\section{Reporting for specific materials, systems and methods}

We require information from authors about some types of materials, experimental systems and methods used in many studies. Here, indicate whether each material, system or method listed is relevant to your study. If you are not sure if a list item applies to your research, read the appropriate section before selecting a response.

\begin{tabular}{l|l} 
Materials \& experimental systems \\
\hline$n / a$ & Involved in the study \\
\hline & $\square$ Antibodies \\
$\square$ & $\square$ Eukaryotic cell lines \\
$\square$ & $\square$ Palaeontology and archaeology \\
$\square$ & $\square$ Animals and other organisms \\
$\square$ & $\square$ Human research participants \\
$\square$ & $\square$ Clinical data \\
$\square$ & $\square$ Dual use research of concern
\end{tabular}

\begin{tabular}{|c|c|}
\hline $\mathrm{n} / \mathrm{a}$ & Involved in the study \\
\hline Х & $\square$ ChIP-seq \\
\hline Х & $\square$ Flow cytometry \\
\hline$\bigotimes$ & $\square$ MRI-based neuroimaging \\
\hline
\end{tabular}

\section{Eukaryotic cell lines}

Policy information about cell lines

Cell line source(s)

Authentication

Mycoplasma contamination

Commonly misidentified lines (See ICLAC register)
High Five Cells (ThermoFisher)

HEK 293T (Cell Bank at the Chinese Academy of Sciences)

Used as expression stains only, independent verification after purchase not required.

Cell lines were tested and free from mycoplasma contamination.

No commonly misidentified cell lines were used. 